\title{
Glutaminase-Deficient Mice Display Hippocampal Hypoactivity, Insensitivity to Pro-Psychotic Drugs and Potentiated Latent Inhibition: Relevance to Schizophrenia
}

\author{
Inna Gaisler-Salomon ${ }^{1,5}$, Gretchen M Miller ${ }^{1,5}$, Nao Chuhma ${ }^{1,5}$, Sooyeon Lee ${ }^{1,5}$, Hong Zhang ${ }^{4}$, \\ Farhad Ghoddoussi ${ }^{8}$, Nicole Lewandowski ${ }^{2}$, Stephen Fairhurst ${ }^{6}$, Yvonne Wang ${ }^{1,5}$, Agnès Conjard-Duplany ${ }^{9}$, \\ Justine Masson $^{10}$, Peter Balsam ${ }^{1,6}$, René Hen ${ }^{3,7}$, Ottavio Arancio ${ }^{4}$, Matthew P Galloway ${ }^{8}$, Holly M Moore ${ }^{1,7}$, \\ Scott A Small*,2 and Stephen Rayport*,1,5 \\ 'Department of Psychiatry, Columbia University, New York, NY, USA; ${ }^{2}$ Department of Neurology, Columbia University, New York, NY, USA; \\ ${ }^{3}$ Department of Pharmacology, Columbia University, New York, NY, USA; ${ }^{4}$ Department of Pathology, Columbia University, New York, NY, USA; \\ ${ }^{5}$ Department of Molecular Therapeutics, New York State Psychiatric Institute, New York, NY, USA; ${ }^{6}$ Department of Cognitive Neuroscience, New \\ York State Psychiatric Institute, New York, NY, USA; ${ }^{7}$ Department of Integrative Neuroscience, New York State Psychiatric Institute, New York, \\ NY, USA; ${ }^{8}$ Departments of Psychiatry and Behavioral Neurosciences and Anesthesiology, Wayne State University School of Medicine, Detroit, MI, \\ USA; ${ }^{9}$ INSERM U820, Centre de Métabolomique et Maladies Métaboliques, Faculté de Médecine Laennec, Lyon, France; ${ }^{10}$ INSERM U894, \\ Centre de Psychiatrie et Neuroscience, Faculté de Médecine, Université Paris Descartes - Paris 5, Paris, France
}

\begin{abstract}
Dysregulated glutamatergic neurotransmission has been strongly implicated in the pathophysiology of schizophrenia (SCZ). Recently, presynaptic modulation of glutamate transmission has been shown to have therapeutic promise. We asked whether genetic knockdown of glutaminase (gene GLSI) to reduce glutamatergic transmission presynaptically by slowing the recycling of glutamine to glutamate, would produce a phenotype relevant to SCZ and its treatment. GLSI heterozygous (GLSI het) mice showed about a $50 \%$ global reduction in glutaminase activity, and a modest reduction in glutamate levels in brain regions relevant to SCZ pathophysiology, but displayed neither general behavioral abnormalities nor SCZ-associated phenotypes. Functional imaging, measuring regional cerebral blood volume, showed hippocampal hypometabolism mainly in the CAI subregion and subiculum, the inverse of recent clinical imaging findings in prodromal and SCZ patients. GLSI het mice were less sensitive to the behavioral stimulating effects of amphetamine, showed a reduction in amphetamine-induced striatal dopamine release and in ketamine-induced frontal cortical activation, suggesting that GLSI het mice are resistant to the effects of these pro-psychotic challenges. Moreover, GLSI het mice showed clozapinelike potentiation of latent inhibition, suggesting that reduction in glutaminase has antipsychotic-like properties. These observations provide further support for the pivotal role of altered glutamatergic synaptic transmission in the pathophysiology of SCZ, and suggest that presynaptic modulation of the glutamine-glutamate pathway through glutaminase inhibition may provide a new direction for the pharmacotherapy of SCZ.
\end{abstract}

Neuropsychopharmacology (2009) 34, 2305-2322; do: I 0.1 038/npp.2009.58; published online 10 June 2009

Keywords: glutamate; dopamine; antipsychotic; GLSI; mouse; imaging

\section{INTRODUCTION}

Alterations in glutamatergic synaptic transmission have been repeatedly implicated in the pathophysiology of

\footnotetext{
*Correspondence: Dr Stephen Rayport, Department of Psychiatry, Columbia University, I05I Riverside Drive, NYSPI Unit 62, New York, NY 10032, USA, Tel: + 2125435641 ,

E-mail: sgrl@columbia.edu or

Dr Scott A Small, Department of Neurology, Columbia University, 630 W 168th Street, New York, NY 10032, USA,

Tel: +212 305-9194, E-mail: sas68@columbia.edu

Received 2 March 2009; revised 28 April 2009; accepted 8 May 2009
}

schizophrenia (SCZ). Specifically, it has been proposed that NMDA receptor hypofunction engenders SCZ symptomatology, as PCP and other NMDA receptor blockers induce or exacerbate SCZ-like symptoms in man, and mimic aspects of the disorder in animals (Arguello and Gogos, 2006; Javitt and Zukin, 1991). Although NMDA receptor hypofunction might reflect a state of general glutamate deficiency, animal studies have shown that NMDA receptor antagonists paradoxically potentiate glutamate neurotransmission in cortical and subcortical regions (Moghaddam et al, 1997; Razoux et al, 2007; Takahata and Moghaddam, 2003), and that genetic reductions in glutamate uptake produce mice with putatively elevated glutamate function and SCZ-related 
phenotypes (Karlsson et al, 2008; Karlsson et al, 2009). Recent clinical studies indicate that drugs that reduce excitatory glutamatergic transmission, such as the glutamate release inhibitor, lamotrigine (Hunt et al, 2008; Large et al, 2005; Tiihonen et al, 2003) and the mGlu2/3 agonist, LY404039 (Patil et al, 2007) show therapeutic efficacy in SCZ. Taken together, these studies indicate that the role played by glutamate transmission in SCZ-related pathology is complex, and suggest that reducing glutamate release in mice could engender phenotypes relevant to the psychopathology or pharmacotherapy of SCZ.

Although there are mechanisms for de novo synthesis of glutamate in neurons (Maciejewski and Rothman, 2008), most neurotransmitter glutamate is recycled through the glutamate-glutamine cycle (Hertz and Zielke, 2004), in which phosphate-activated glutaminase 1 (gene GLS1) converts glutamine to glutamate in neurons; astrocytes then take up synaptically released glutamate and convert it to glutamine, which is transported back to neurons (Chaudhry et al, 2002). To date, the glutamate-glutamine cycle has not been directly explored in animal studies of SCZ-related pathophysiology, although there is evidence for pathological alterations in the expression of several molecules participating in the cycle, including glutaminase (Bruneau et al, 2005; Gluck et al, 2002; Steffek et al, 2008), in SCZ. Although homozygous GLS1 null mice (GLS1 knockouts) die shortly after birth, mice heterozygous for the mutation (GLS1 hets) are ostensibly normal (Masson et al, 2006), and so provide a way to address whether a reduction in glutamate recycling might have relevance to SCZ.

In this study, we phenotyped GLS1 het mice on multiple levels, starting by showing that GLS1 haploinsufficiency impacts brain glutamate function. We then asked whether the mice would display phenotypes relevant to the pathophysiology or treatment of SCZ. In a recent fMRI study in SCZ and prodromal populations, we found that SCZ is associated with hippocampal (HIPP) hyperactivity, driven mainly by hyperactivity in the CA1 subfield and the subiculum (SUB) (Schobel et al, 2009). We used a similar fMRI technique to see whether GLS1 hets display SCZ-like HIPP hyperactivity, and continued to phenotype the mice using a multi-level approach, in an attempt to determine how well their imaging, neurochemical, and behavioral phenotypes align with hallmark findings in human and animal studies of SCZ.

\section{METHODS}

Detailed methodology for all procedures, with the exception of generation and care of mice, is provided in the Supplementary Information (SI).

\section{Mice}

GLS1 het mice were made by insertion of a floxed PGKneoStop cassette through homologous recombination ahead of the transcription initiation site in exon 1 of the GLS1 gene (Entrez Gene 14660), as described earlier (Masson et al, 2006). The GLS1 mutant colony was kept on a mixed background 129SvEv/J-C57BL6/J. Mice were obtained from crosses of GLS1 hets and wild-type (WT) mice (heterozygous breeding). Animals were maintained on a 12 -h light-dark cycle; all experiments were performed during the light phase. Experiments were conducted on adult mice 3-6 months of age, using matched WT littermates as controls. Male mice were used throughout, except for the electrophysiological recordings (where both male and female mice were used). Procedures involving mice and their care were conducted in conformity with the institutional guidelines of the National Institutes of Health Guide for the Care and Use of Laboratory Animals and performed under protocols approved by the Institutional Animal Care and Use Committees of Columbia University and New York State Psychiatric Institute. Food and water were provided ad libitum, except for the delayed nonmatch/match to sample and interval timing experiments (see below, and SI).

\section{Enzymatic Activity}

Tissue preparation and measurement of glutaminase activity were performed according to the established procedures (Conjard et al, 2002; Curthoys and Lowry, 1973). Enzymatic activity of glutaminase was expressed as micromoles of glutamate produced per $\mathrm{mg}$ protein per hour.

\section{${ }^{1} \mathrm{H}$ Magnetic Resonance Spectroscopy}

High-resolution magic angle spinning ${ }^{1} \mathrm{H}$ magnetic resonance spectroscopy (HR-MAS ${ }^{1} \mathrm{H}$ MRS) tissue collection, data acquisition and spectrum analysis were performed on intact tissue samples as described earlier (O'Leary-Moore et al, 2007). Absolute concentrations of MRI-visible metabolites (Supplementary Information, Figure S1) were corrected for wet tissue weight and expressed as $\mathrm{nmol} / \mathrm{mg}$.

\section{Immunocytochemistry}

The immunostaining procedure was performed using a monoclonal antiserum directed against the carbodiimide conjugate of glutamate, as described earlier (Madl et al, 1986). Mean intensities were calculated from the pixel intensity histograms generated from image mosaics.

\section{Behavioral Testing}

Locomotor activity in the open field. Baseline and amphetamine-induced locomotor activity in the open field was measured following the established methodology (Paterlini et al, 2005). The total distance traveled during successive 10-min bins was recorded and analyzed.

Rotarod. Motor learning was determined using an accelerating rotarod apparatus, as described earlier (Sharma et al, 2005). Latency to fall off the accelerating rotarod was recorded and analyzed.

Light-dark emergence test. The light-dark emergence test was conducted as described earlier (Belzung et al, 1987). The time spent in the light and dark compartments was recorded, as were the number of transitions between compartments and the total ambulatory distance in each compartment. 
Prepulse inhibition of startle. Prepulse inhibition of startle was measured as described earlier (Paylor and Crawley, 1997). Maximum startle amplitude, averaged across trials for each of the three prepulse intensities that were used, was the dependent variable. Percent prepulse inhibition (PPI) of the startle response was calculated as follows:

$$
\left[1-\frac{\text { startle response on prepulse }+ \text { pulse trials }}{\text { startle response on pulse }- \text { alone trials }}\right] \times 100
$$

Delayed non-match/match-to-sample. The test was performed as described earlier (Dias and Aggleton, 2000; Kellendonk et al, 2006), with slight modifications. Briefly, testing was conducted in a Y maze and consisted of two consecutive tasks: a delayed non-match-to-sample (DNMTS) task and a delayed match-to-sample (DMTS) task. In the DNMTS phase, mice were tested in four trials per day, each trial began with a forced run, in which mice collected a food reward from a randomly chosen left or right arm while the entrance to the other arm remained closed, and continued after an interval of $4 \mathrm{~s}$ with a choice run, in which both arms were opened and a correct choice was scored when the mouse visited the arm opposite to that visited on the forced run. The number of correct trials was recorded. The number of days required to reach criterion (11 out of 12 choices over 3 days) was assessed for each mouse.

A subset of the mice that completed the DNMTS task continued on to a MTS task, in which mice in the choice run were reinforced for visiting the same arm as in the forced run. The number of days required to reach criterion, that is, to switch from the perseverative ( $<2$ out of 4 correct trials) to the learning phase ( $\geqslant 2$ out of 4 trials), was assessed for each mouse (Dias and Aggleton, 2000).

Fixed-interval conditioning and interval timing. Fixedinterval (FI) conditioning and interval timing were measured as described earlier (Drew et al, 2007). Briefly, FI training began following the operant lever-press training, in which mice learned to consume the liquid reward from a dipper and to press a lever to earn reward. In FI training, lever presses were reinforced after a minimum interval had elapsed from the bar extension until reward became available. Mice began on FI-4s schedule, and progressed to $4,8,12$ and $16 \mathrm{~s}(16 \mathrm{~s})$ FI durations. When a mouse reached the criterion of 40 rewards in one session on the FI$16 \mathrm{~s}$ schedule it was moved to peak interval (PI) training. PI training consisted of two trial types: Fixed-interval FI-16s trials (as described above) and Peak trials, in which the lever was extended for $64 \mathrm{~s}$ but lever presses were not reinforced. On these trials, the likelihood of responding increases as the expected time of reward (ie, 16s) approaches, and then declines. Response rates (responses/s) and latency to respond during FI training and PI trials were recorded and analyzed.

Fear conditioning to tone and context. Fear conditioning was performed according to the standard procedure, as described earlier (Saxe et al, 2007). The percent of time spent freezing was assessed using FreezeFrame software during conditioning (day 1), tone test (day 2), and context test (day 3). On day 1 , freezing was scored during the $20 \mathrm{~s}$ of each tone presentation. On day 2, freezing was scored for the $20 \mathrm{~s}$ before the first tone presentation (pre-tone freezing) and during the $20 \mathrm{~s}$ of the first tone presentation (tone-period freezing). On day 3 , the entire context test session was scored for freezing.

Morris Water Maze. Testing was conducted according to the standard procedure, as described earlier (Saxe et al, 2007), with slight modifications. Briefly, after a 2-day habituation, visible platform training (day 3) and hidden platform training (days 4-11) were performed, followed by two probe trials conducted $1 \mathrm{~h}$ and 7 days after the last hidden platform training session. During platform training, time (s) to reach the platform was recorded and analyzed on each trial. On probe trials, percent time in each quadrant was recorded and analyzed.

Novel object recognition. Testing was conducted according to the established methodology (Ennaceur and Delacour, 1988). Briefly, the Novel Object Recognition Test was conducted in two phases, a sample and a retention test phase. Object exploration times during both phases were recorded and analyzed.

Latent inhibition. Testing was conducted according to the established methodology (Yee et al, 2006). Freezing behavior was assessed using FreezeFrame software during the four phases of the procedure as follows: pre-exposure, conditioning, context test, and tone test. Pre-exposure and conditioning were conducted consecutively, on day 1 of the experiment. Clozapine $(1.5 \mathrm{mg} / \mathrm{kg})$ was injected i.p. on day 1, $30 \mathrm{~min}$ before the behavioral procedure. On the tone test day, percent pre-tone freezing was defined as the average freezing during the $180 \mathrm{~s}$ preceding tone onset. The freezing ratio for each animal was calculated using the formula $\mathrm{B} /(\mathrm{A}$ $+B)$, in which $A$ is the percent freezing during the $30 \mathrm{~s}$ immediately preceding tone onset and $\mathrm{B}$ the percent freezing during the tone.

\section{In Vivo Imaging}

A modified mouse imaging protocol (Moreno et al, 2007; Pereira et al, 2007) was used for generating baseline and post-ketamine relative cerebral blood volume (rCBV) maps. Briefly, seven sets of axial T2-weighted images were acquired sequentially. The contrast agent gadodiamide was injected (13 mmol/kg i.p.) after a pre-contrast set. Ketamine $(30 \mathrm{mg} / \mathrm{kg})$ was injected through the catheter after three post-contrast sets. The last three sets corresponded to the post-ketamine post-contrast images. Normalized rCBV measurements from each subregion were used for group data analysis.

\section{Slice Physiology}

Spontaneous EPSCs (sEPSCs) were recorded under $\mathrm{GABA}_{\mathrm{A}}$ blockade from CA1 pyramidal neurons (HIPP) or large pyramidal neurons in layer V/VI (anterior cingulate) slices, as described earlier (Masson $e t$ al, 2006). The amplitude and frequency of sEPSCs were recorded and analyzed. 
Measurements of synaptic strength in HIPP slices were done at $29^{\circ} \mathrm{C}$. CA1 field EPSPs (fEPSPs) were evoked and recorded as described earlier (Yano et al, 2006) with both stimulating and recording electrodes in the CA1 stratum radiatum. Stimulus voltages $(V)$ was plotted against the slope of the fEPSP to determine the input-output relationship. All electrophysiology experiments were done blind to genotype.

\section{Microdialysis}

WT-GLS1 het yoked pairs were stereotaxically implanted with microdialysis guide cannulae in the striatum. On the in vivo microdialysis session, mice were placed in testing chambers for $30-45 \mathrm{~min}$, and microdialysis probes were slowly inserted to extend $2 \mathrm{~mm}$ beyond the tip of the guide cannulae, and perfused with an artificial cerebrospinal fluid $(\mathrm{aCSF})$ at a flow rate of $2.0 \mu \mathrm{l} / \mathrm{min}$. Dialysate collection began $2.5 \mathrm{~h}$ after probe insertion, and consisted of four consecutive 15-min baseline samples. Amphetamine was then administered $(2.0 \mathrm{mg} / \mathrm{kg}$, i.p) and four more $15-\mathrm{min}$ samples collected. Probe placement in the medial or central striatum was verified in Nissl-stained sections (Supplementary Information, Figure S2). Quantification of dopamine (DA) in the dialysis samples was performed by highpressure liquid chromatography with electrochemical detection. Concentrations of DA and its metabolites were quantified using an external standard curve from standards prepared in the same aCSF/preservative mixture as the brain dialysates.

\section{Statistical Analysis}

Behavioral and electrophysiological data were subjected to $t$-tests or to ANOVA analysis using JMP (SAS, Cary, NC) or SPSS (Chicago, IL). Fisher's least statistical difference (LSD) post hoc tests were conducted to test differences between groups when interactions were statistically significant. Significance level was set to $p<0.05$. For the microdialysis experiments, a matched-pairs design was used, allowing for comparisons within related WT-GLS1 het pairs. As similarly normal distributions of DA values across genotypes could not be assumed, the Wilcoxon test for related pairs was used. Post hoc power analysis was performed using $\mathrm{G}^{*}$ Power 3.0.10 (Faul et al, 2007).

\section{RESULTS}

\section{Reduction of Glutaminase Activity in the Brains of GLS1 hets}

We showed earlier that GLS1 message was decreased to about half in GLS1 hets (Masson et al, 2006). However, enzymatic activity may remain near normal despite significant reductions in expression. Thus, we first assessed glutaminase activity in whole brain, and found that it was reduced by about $50.0 \%$, with GLS1 het brain showing activity of $9.8 \pm 0.5$ and WT brain showing an activity of $19.6 \pm 1.2$ micromoles per mg protein per hour $(n=13$; independent samples $t$-test, $p<0.0001)$. We then examined regional glutaminase activity in the frontal cortex (FC), HIPP, and thalamus (THAL), and found glutaminase activity to be significantly reduced in all three regions
( $n=12$, repeated-measure ANOVA with genotype as the between-subject factor and region as the within-subject factor, main effect of genotype, $\mathrm{F}(1,10)=42.6, p<0.0001$, no main effect of region or genotype $\times$ region interaction $p$ values $>0.1$ ). Activity levels were reduced to $40.2,45.9$, and $41.8 \%$ of WT levels in the FC, HIPP, and THAL, respectively (Figure 1a).

\section{GLS1 hets Have Reduced Levels of Glutamate in FC And Hippocampus}

Glutaminase is constitutively active in the brain but subject to end product inhibition, so despite the $50 \%$ inhibition in activity, there might be sufficient reserve activity to maintain normal glutamate levels (Curthoys and Watford, 1995). Therefore, we used HR-MAS ${ }^{1}$ H-MRS to measure levels of glutamate and related neurochemicals in tissue punches from FC, HIPP, and THAL of GLS1 hets and their WT littermates. The experiment included 25 samples from FC, 15 samples from HIPP, and 15 samples from THAL. Data were analyzed with unpaired two-tailed $t$-tests comparing WT and GLS1 het mice in each region. We found that glutamate levels were reduced in GLS1 hets (Figure $1 \mathrm{~b} 1)$ by $16 \%$ in the FC $(p<0.005)$ and $13 \%$ in the HIPP $(p<0.05)$. Reductions in glutamate levels were accompanied by increased glutamine levels, and reduced glutamate-glutamine ratios (Figure $1 \mathrm{~b} 2$ ), in the FC $(p<0.05)$, HIPP $(p<0.005)$, and THAL $(p<0.05)$. Several other neurochemicals, including myo-inositol, lactate, and GABA, were altered in the HIPP of GLS1 het mice (Supplementary Information, Figure S1b).

To verify the decreases in glutamate further, tissue sections were immunostained with Glu2, a mouse monoclonal antibody directed against carbodiimide-conjugated glutamate (Madl et al, 1986). The experiment included 21 sections from FC, 26 from HIPP, and 18 from THAL. Data were analyzed with unpaired two-tailed $t$-test comparing WT and GLS1 het mice and showed reductions in glutamate-associated fluorescence (Figure 1c) in the FC $(p<0.005)$ and HIPP $(p<0.05)$, with a trend in THAL $(p=0.078)$.

\section{GLS1 hets Show no Alteration in Basic Behavioral Measures}

To determine whether the glutamate deficiency in GLS1 hets is associated with behavioral abnormalities, we carried out a broad-based behavioral screen to assess baseline locomotor activity, sensory gating, motivation, cognitive function, and behavior relevant to SCZ psychopathology.

Baseline locomotor activity. Abnormal locomotor activity levels may point to underlying neurological, motor, or motivational deficits. In the context of SCZ, hyperactivity in animal models can be associated with increased dopaminergic transmission (Arguello and Gogos, 2006; Karlsson et al, 2008), one of the hallmark findings in SCZ, with special relevance to positive symptoms (Arguello and Gogos, 2006). We tested locomotor activity in drug-naïve GLS1 hets and their WT littermates. The experiment included 42 mice. Data were analyzed with a repeatedmeasure ANOVA, with genotype as the between-subject factor and testing time as the within-subject factor. 

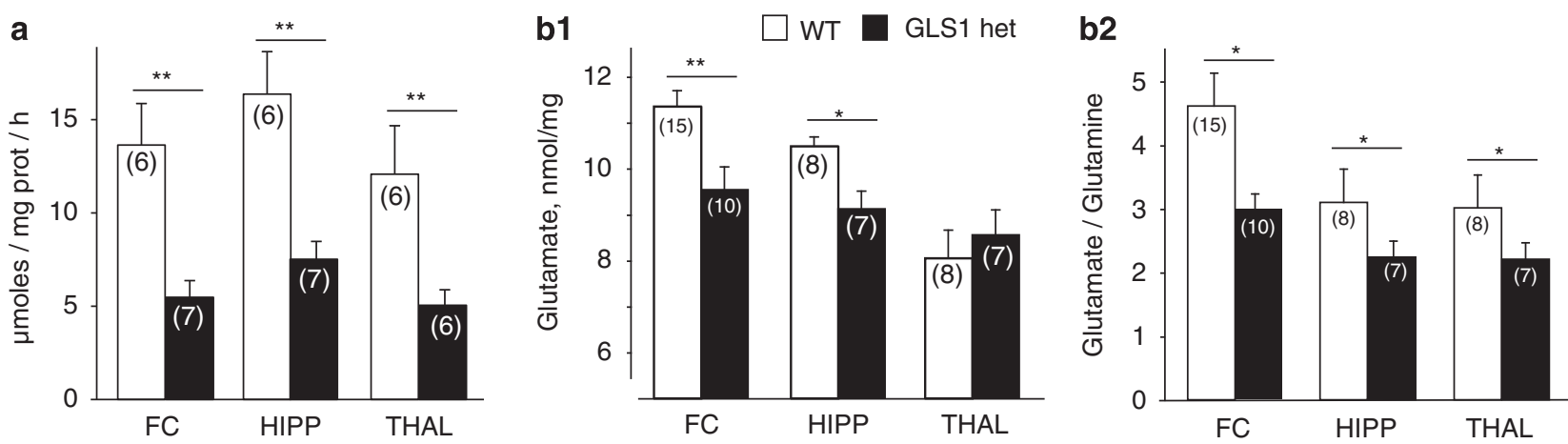

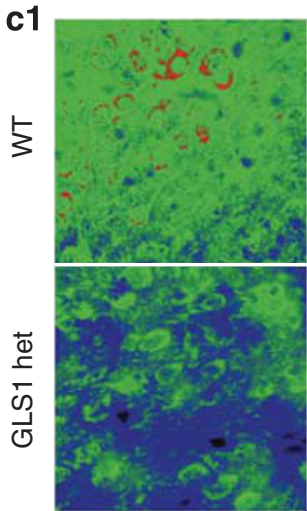

FC

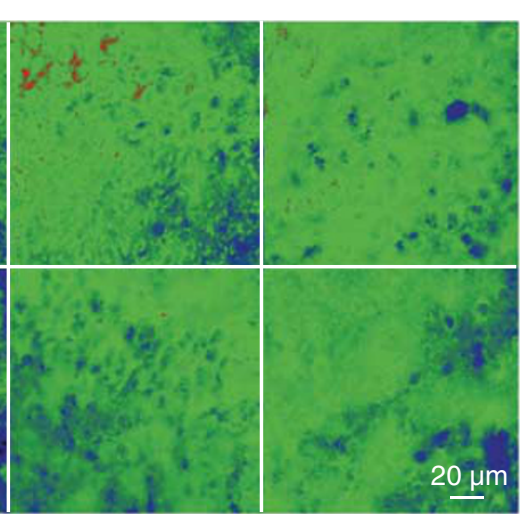

HIPP

THAL

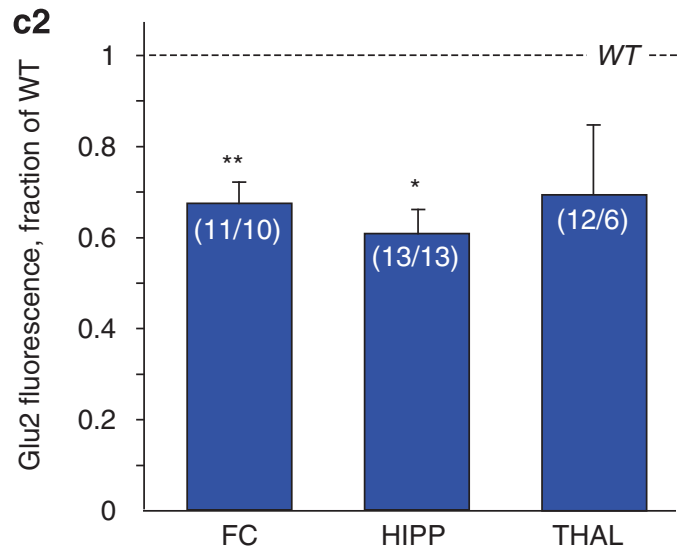

Figure I Reduced glutaminase activity and glutamate levels in GLSI hets. (a) Glutaminase activity was assessed in the FC, HIPP, and THAL of GLSI hets and WT littermates. Activity was significantly reduced in GLSI hets in all regions. WT $>$ GLSI hets $* * P<0.000$ I. (b) Glutamate levels in the FC, HIPP, and THAL of GLSI hets and WT littermates were assessed using ex-vivo HR-MAS ${ }^{1} H$ MRS. (b I) Glutamate (nmol/mg of wet tissue) was reduced in the FC and HIPP of GLSI hets. WT $>$ GLSI hets, *p $<0.05$, *** $<0.005$. (b2) Glutamate-glutamine ratios were reduced in the FC, HIPP, and THAL of GLSI hets. $W T>$ GLSI hets, *p<0.05. (c) Glutamate was measured in tissue sections by immunocytochemistry with the glutamate-specific antibody Glu2. (cl) Representative micrographs from FC, HIPP, and THAL sections in WT (top) and GLSI hets (bottom) are shown in pseudocolor with warmer colors reflecting higher glutamate levels. (c2) Ratio of GLSI het/WT immunofluorescence, quantified from $40 \times$ micrographs. Ratios were reduced in the FC and HIPP. Ratio GLSI hets/WT < I, * $p<0.05$, ** $p<0.005$. In all figures, n's are given in parentheses (in c2, n's are GLSI het/MT), and error bars indicate standard errors.

As can be seen in Figure 2a, the total ambulatory distance traveled by GLS1 hets over a period of $30 \mathrm{~min}$ did not differ from that of their WT littermates (no main effect of genotype $\mathrm{F}(1,40)<1$, NS). A time-dependent decrease in locomotor activity (habituation) was observed for both WT mice and GLS1 hets (main effect of time $\mathrm{F}(2,80)=16.24, p<0.0001$, no time $\times$ genotype interaction $\mathrm{F}(2,80)<1, \mathrm{NS})$.

Rotarod. The latency to fall off an accelerating rotarod is commonly used to assess coordination and balance, and the rate of improvement over repeated training as a measure of motor learning (Sharma et al, 2005). The experiment included 20 mice. Data were analyzed with a repeatedmeasure ANOVA, with genotype as the between-subject factor and session as the within-subject factor. As can be seen in Figure 2b, GLS1 hets and their WT littermates exhibited similar latencies across testing sessions (no main effect of genotype $\mathrm{F}(1,18)=1.25, p>0.1)$. An improvement in performance across sessions was observed for both genotypes (main effect of session $\mathrm{F}(5,90)=45562$, $p<0.0001$, no session $\times$ genotype interaction $\mathrm{F}(5,90)<1$, $\mathrm{NS}$ ), indicating that motor learning in GLS1 het mice was not impaired.
Light-dark emergence. Alterations in glutamatergic synaptic function have been associated with anxiety phenotypes (Tordera et al, 2007). To address this, we conducted the light-dark emergence test. The experiment included 15 mice. Data were analyzed with unpaired two-tailed $t$-tests comparing GLS1 hets to their WT littermates. GLS1 hets showed no genotypic differences in the time spent in the light to dark compartment ( $p>0.5$, Figure $2 c$, left panel). Similarly, there were no genotypic differences in the number of transitions between compartments $(p>0.1$, data not shown), or in total ambulatory distance during the 5 min test session ( $p>0.5$, data not shown).

Prepulse inhibition of startle. Prepulse inhibition of startle is an operational measure of sensorimotor gating, a pre-attentive filtering process (Geyer et al, 2002), and an indication of intact sensory discrimination capacities (Fitch et al, 2008). PPI is widely used to assess SCZ-related dysfunction of limbic striatal circuits in rodent models, and normalization of PPI has high predictive validity with regard to antipsychotic efficacy (Braff et al, 2001; Geyer et al, 2002). The experiment included 27 mice. Data were analyzed with repeatedmeasures ANOVA, with genotype as the between-subject 
a

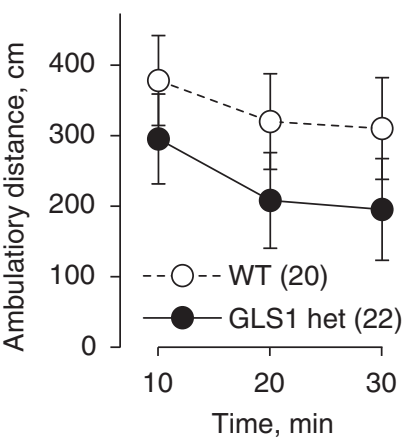

d $\square$ WT (15) $\quad$ GLS1 het (12)

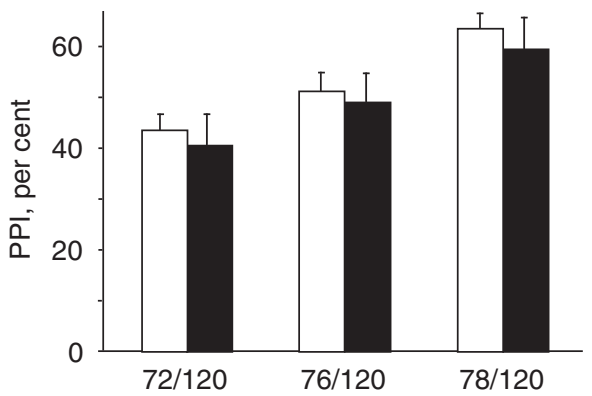

f1

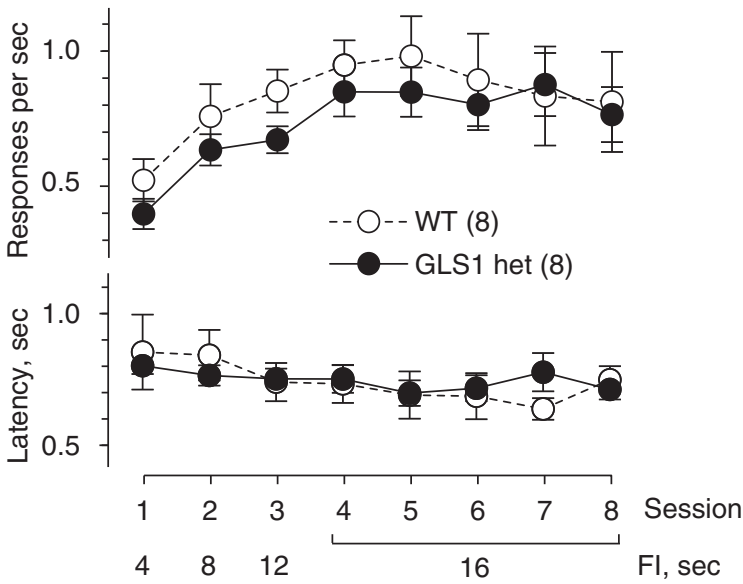

b

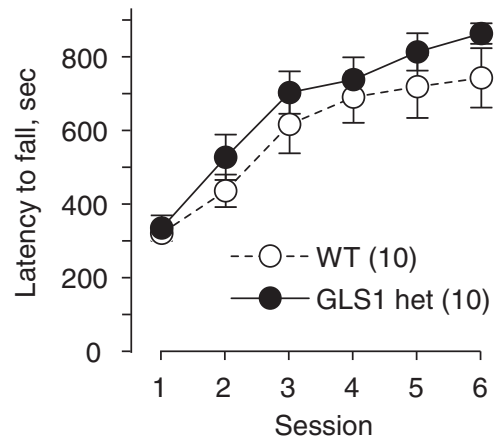

e1

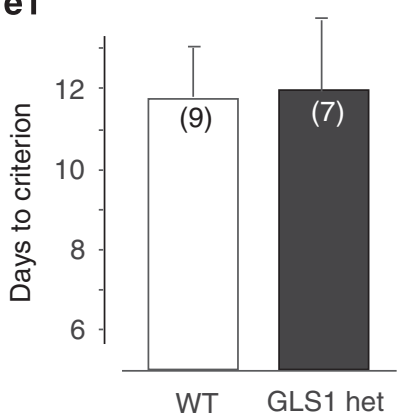

f2

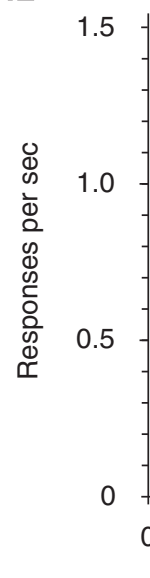

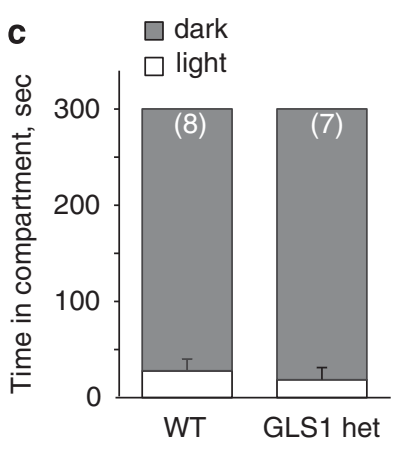

e2

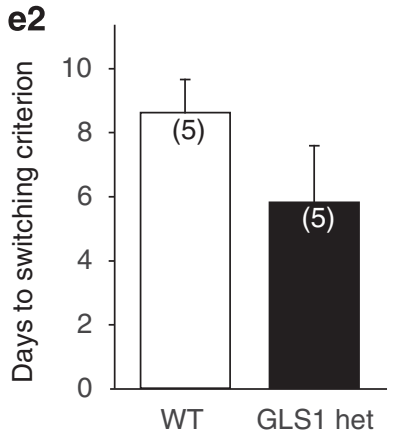

Figure 2 Normal behavioral repertoire of GLSI hets across a range of tests. (a) When placed in the open field, GLSI hets and WT littermates showed similar levels of locomotor activity and habituation over $30 \mathrm{~min}$. (b) Both genotypes showed similar latency to fall from an accelerating rotarod, with a parallel improvement in performance over six learning sessions. (c) In the light-dark emergence test, there were no genotypic differences in the time spent in the light $(\square)$ vs dark $(\mathbf{\square})$ compartments of the open field over the 5-min test period. (d) Startle responses showed no genotypic differences. When the startle pulse ( $120 \mathrm{~dB}$ ) was preceded by prepulses of increasing intensity $(72,76,78 \mathrm{~dB})$, GLSI hets and their WT littermates showed similar prepulse inhibition (PPI). (e) Performance in the Y-maze task was unaffected. Both genotypes required the same number of days needed to reach criterion during the delayed non-match-to-sample (DNMTS) phase (el) and the delayed match-to-sample (DMTS) phase (e2) of a Y-maze task. (f) Performance in an operant interval timing task showed no genotypic motivation differences. During training, the response rate ( $\mathrm{fl}$, top) and latency to first lever press ( $\mathrm{fl}$, bottom) were identical across sessions of increasing Fl duration. There were no genotypic differences in timing accuracy ( $(2)$. As shown in the inset, on fixed interval trials (FI trials, top), mice were rewarded for bar pressing after 16s, whereas on Peak trials (bottom), the accuracy of timing the $16 \mathrm{~s}$ interval was assessed during a 64-s non-reinforced epoch. For both GLSI hets and WT littermates, the likelihood of responding peaked around the expected time of reward (ie, $16 \mathrm{~s}$ ), then declined.

factor and prepulse intensity as the within-subject factor. Although the PPI effect was enhanced with increasing prepulse intensity, in GLS1 hets we observed no abnormalities in PPI at any of the three prepulse intensities used (Figure 2d; main effect of prepulse intensity $\mathrm{F}(2,23)=40.4$, $p<0.0001$, no main effect of genotype or genotype $\times$ prepulse intensity interaction, $p$-values $>0.1$ ).

Delayed non-match/match-to-sample. We assessed the behavior of GLS1 hets and their WT littermates in a task 
that involves working memory and behavioral flexibility, and requires intact prefrontal cortex function (Dias and Aggleton, 2000; Kellendonk et al, 2006). Deficits in delayed non-match-to-sample (DNMTS) have been viewed as a proxy for the negative and cognitive deficits in SCZ in mice (Kellendonk et al, 2006; Morice, 1990). The DNMTS and DMTS parts of the experiment included 16 and 10 mice, respectively. Data were analyzed with unpaired two-tailed $t$-tests comparing GLS1 hets with their WT littermates. In the first part of the experiment, which required acquisition of the non-match-to-sample rule, we found no genotypic difference in the number of days required to reach criterion (Figure $2 \mathrm{e} 1 ; p>0.5$ ). With the cognitive set shift to the match-to-sample rule (Figure 2e2), there was no genotypic difference in the time required for mice to switch response strategies $(p>0.5)$.

Fixed-interval training and interval timing. The intervaltiming (IT) task relies on an operant lever-pressing paradigm, and provides a measure of both appetitive motivation and the ability to time reward. To assess motivation, we measured the response rates and latencies to respond across training sessions with an increasing FI. The experiment included 16 mice. Data were analyzed with repeated-measures ANOVA, with genotype as the betweensubject factor and testing session as the within-subject factor. Both GLS1 hets and their WT littermates displayed an increase in response rates as the FI increased across sessions (Figure 2fl, top: main effect of session, $\mathrm{F}(7,98)=6.27, p<0.0001)$; no genotypic differences were observed (main effect of genotype $\mathrm{F}(1,14)<1$, NS, genotype $\times$ session interaction $F(7,98)<1$, NS). Similarly, both genotypes showed decreased latencies to respond across sessions (Figure 2f1, bottom; main effect of session, $\mathrm{F}(7,98)=2.29, \quad p<0.05)$; no genotypic differences were observed (main effect of genotype $\mathrm{F}(1,14)<1$, NS, genotype $\times$ session interaction $\mathrm{F}(7,98)=1.07, p>0.1)$. GLS1 het mice, therefore, show no deficit in their anticipatory motivation to work for rewards nor do they show a deficit in how they react to a reward once presented.

To assess temporal information processing, we measured performance on PI trials. Accurate performance on an interval timing task tests a range of important cognitive processes, characteristically impaired in SCZ (Elvevag et al, 2004; Elvevag et al, 2003). To characterize the relative timing abilities, we examined the distributions of leverpress responses during the peak trials. In these trials, the response rate is expected to increase as the expected time of reward (ie, 16s) approaches, and then to decline after the expected time of reward passes (Figure 2f 2 , inset). As timed responding of this sort usually develops gradually with training, we plotted the number of responses per second during peak trials, averaging across all peak trials in the last five sessions of training (sessions 7-11), which is the period in which control mice exhibit asymptotic performance in terms of both response rate and timing precision. The experiment included 15 mice. Data were analyzed with a repeated-measure ANOVA, with genotype as the betweensubject factor and time as the within-subject factor. The shapes and peak heights of GLS1 het and WT response rate curves were indistinguishable (Figure $2 \mathrm{f} 2$ ), indicating that the ability of GLS1 hets to time reward was intact (main effect of time $\mathrm{F}(63,819)=90.86, p<0.0001$, no main effect of genotype $\mathrm{F}(1,13)<1$, NS, no genotype $\times$ time interaction $\mathrm{F}(63,819)=1.11, p>0.1)$. Thus, temporal processing seems to be normal in GLS1 hets.

We performed a post hoc power analysis and found that with the exception of light-dark emergence and the DNMTS, experiments were sufficiently powered to detect even small differences in behavior (Cohen, 1988).Viewed as a group, these behavioral assays indicate that there are no baseline behavioral abnormalities in GLS1 hets.

\section{GLS1 hets Have a Hypofunctional Hippocampus}

Baseline rCBV. To see whether GLS1 hets display SCZ-like HIPP hyperactivity (Schobel et al, 2009), we used a CBVbased fMRI approach to generate rCBV maps. We measured mean $\mathrm{rCBV}$ values in the FC, the HIPP, and the THAL. The experiment included 21 mice. Data were analyzed with a multivariate repeated-measure analysis of variance, with genotype as the between-subject factor and rCBV values from the different brain regions as the within-subject factor. Representative images of rCBV in the HIPP and FC are depicted in Figure 3a and b, respectively. We found that there was in GLS1 hets a focal reduction in HIPP rCBV $(\mathrm{F}(1,21)=7.4, p<0.05)$, with no effect in the FC or THAL (Figure 3c1). A further analysis of HIPP subregions (Figure $3 \mathrm{c} 2$ ) showed a predominant reduction in the CA1 $(\mathrm{F}(1,21)=4.8, p<0.05)$ and SUB $(\mathrm{F}(1,21)=5.90, p<0.05)$ of GLS1 hets, with a near-significant reduction in the CA3 subfield $(\mathrm{F}(1,21)=4.81, p=.056)$. Thus, GLS1 hets show a pattern of focal hypoactivity in HIPP subregions, particularly in CA1 and SUB.

Hippocampal synaptic function. To determine whether the alterations in HIPP $\mathrm{rCBV}$ were indicative of alterations in neuronal activity, we examined synaptic function in HIPP slices. We first recorded sEPSCs as a measure of baseline glutamate transmission (Figure $4 \mathrm{a}$ ). The experiment included seven GLS1 het and five WT mice (12 slices and 14 cells from GLS1 hets, 10 slices and 14 cells from WT littermates). Representative traces of sEPSCs are shown in Figure 4a1. Frequency and amplitude data were analyzed with two-tailed $t$-test, and cumulative amplitude data were analyzed with the Kolmogorov-Smirnov two-sample test comparing GLS1 hets with their WT littermates. Under $\mathrm{GABA}_{\mathrm{A}}$ blockade with gabazine (SR95531; $10 \mu \mathrm{M}$ ), sEPSCs recorded from CA1 pyramidal neurons in GLS1 hets showed a marked reduction in frequency compared with WT $(p<0.05$, Figure 4a2), with no reduction in sEPSC amplitude $(p>0.5$, Figure $4 \mathrm{a} 3)$, and no change in the cumulative amplitude distribution $(p>0.5$; data not shown). We did similar recordings in the anterior cingulate cortex; the experiment included three GLS1 het and three WT mice. There were no genotypic differences in sEPSC frequency, amplitude or cumulative amplitude distribution $(n=5$ slices and 9 cells from GLS1 hets, 6 slices and 10 cells from WT littermates; all $p$-values $>0.1$; Figure $4 \mathrm{~b}$ ).

To measure the strength of glutamate transmission in a defined synaptic connection, we assessed the input-output (I-O) relationship for fEPSPs evoked by Schaeffer collateral stimulation and recording in CA1. The experiment included six GLS1 het and six WT mice (8 slices from GLS1 het and 
a1

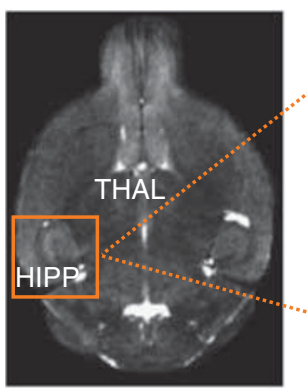

b1

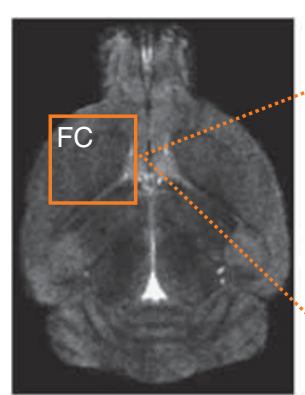

a2

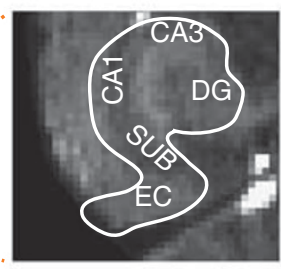

b2

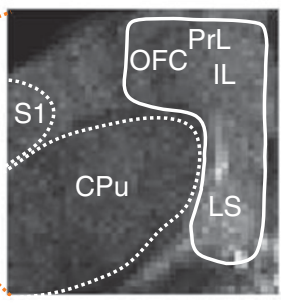

a3
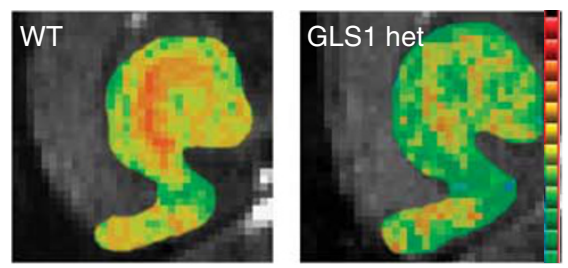

b3
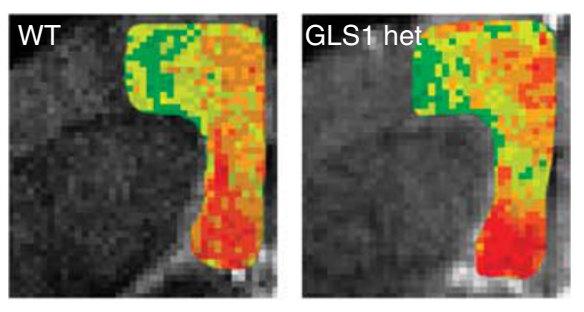

c1

c2
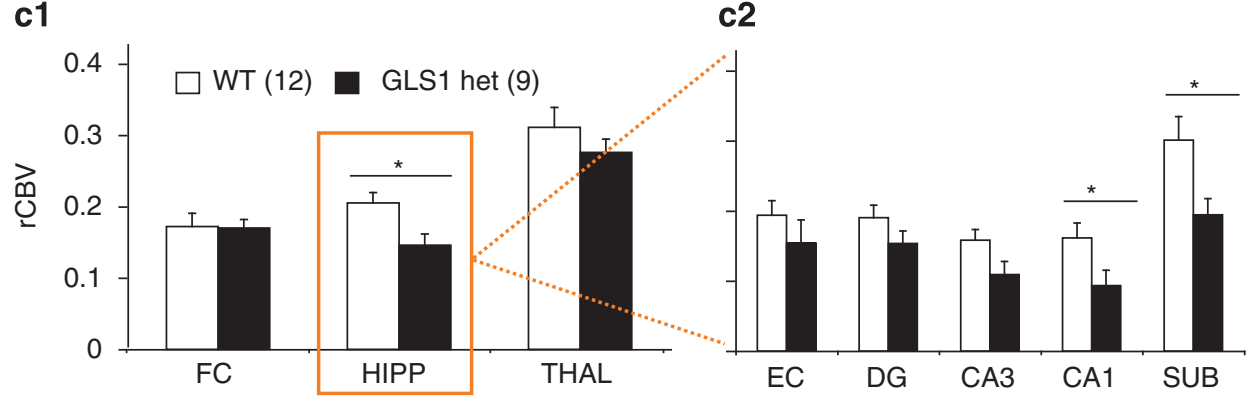

Figure 3 Relative cerebral blood volume ( $\mathrm{CCBV}$ ) is selectively reduced in the HIPP of GLSI hets. (a) Structural MRI slice through the HIPP and THAL in the horizontal plane (al) showing the regions imaged. (a2) higher-resolution structural image of HIPP subregions corresponding with rCBV maps of the HIPP (a3) in WT (left) and GLSI hets mice (right). There were focal reductions in activity in GLSI hets (warmer colors reflect higher rCBV). (b) Structural MRI slice through the FC (bI) to show regions imaged. In a higher resolution image of FC and adjacent regions (b2). rCBV maps (b3) in WT mice (left) and GLSI-hets (right) showed no differences. (c) Summary data showed that GLSI hets have reduced rCBV in the HIPP, but not in the FC or THAL. WT $>$ GLSI hets, $* 2<0.05$ (cl). In the HIPP, rCBV was significantly reduced in the SUB and CAI (c2). WT $>$ GLSI hets, *p $<0.05$. In all figures, n's per group are given in parentheses, and error bars indicate standard errors. Anatomical abbreviations: HIPP-hippocampus, FC-frontal cortex, THAL-thalamus, CAI-CAI subfield of HIPP, CA3-CA3 subfield, DG-dentate gyrus, EC-entorhinal cortex, SUB-subiculum, IL-infralimbic cortex, PrL-prelimbic cortex, OFCorbitofrontal cortex, LS-lateral septum, CPu-caudate-putamen, SI-sensory area I.

7 slices from WT mice). The data were analyzed with a repeated-measure ANOVA, with genotype as the betweensubject factor and stimulus intensity as the within-subject factor. We found a significant reduction in fEPSP slope in GLS1 hets compared with WT over the full I-O curve (repeated-measure two-way ANOVA, genotype $\times$ stimulus intensity interaction $\mathrm{F}(1,143)=5.25, p<0.001$ and post hoc tests $p$-values $<0.05$ at stimulus intensities of $15,25,30$ and $35 \mathrm{~V}$; Figure 4c). Together the slice recording studies confirm a reduction in glutamatergic synaptic transmission, and suggest that this reduction is HIPP-specific.

Hippocampus-dependent behavior. To determine whether decreased glutamate transmission and rCBV in the HIPP has behavioral consequences, we tested GLS1 hets on HIPPrelevant tasks. We measured contextual fear conditioning, which requires HIPP-mediated processing and retrieval of contextual information (Honey and Good, 1993; Jarrard, 1995; Kim and Fanselow, 1992), as well as cued fear conditioning, which strongly depends on amygdala input (LeDoux et al, 1990). The experiment included 26 mice. The data from day 1 (acquisition) were analyzed with a repeated-measure ANOVA, with genotype as the betweensubject factor and CS-US pairing as the within-subject factor. We found that both GLS1 hets and their WT littermates showed conditioned fear (main effect of CS-US pairing, $\mathrm{F}(2,19)=24.9, p<0.0001$, Figure 5a1). Data from day 2 (tone test) were analyzed with a repeated-measure ANOVA, with genotype as the between-subject factor and tone presentation as the within-subject factor. During the tone test, mice of both genotypes froze significantly more during the tone than during the pre-tone period (main effect of tone presentation, $\mathrm{F}(1,21)=14.9, p<0.005$, no genotype $\times$ tone presentation interaction $\mathrm{F}(1,21)<1$, NS; Figure 5a2). Data from day 3 (context test) were analyzed with a one-way ANOVA, with genotype as the main factor. GLS1 hets froze significantly less during the context test period (main effect of genotype, $\mathrm{F}(1,23)=4.6, p<0.05$; 
a1

WT

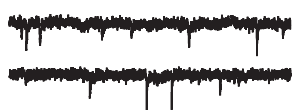

a2

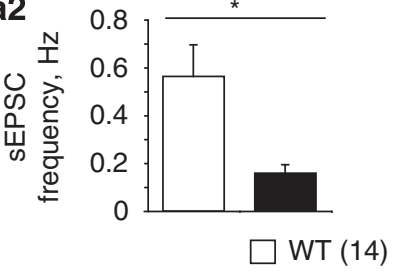

b1

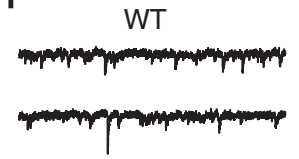

b2

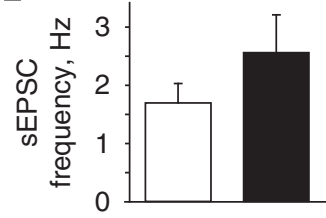

WT (9)

C

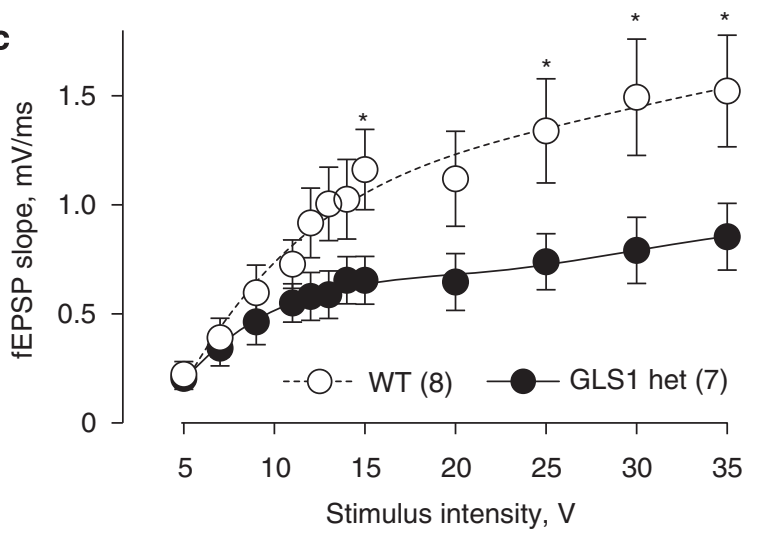

Figure 4 GLSI hets show HIPP-selective reductions in excitatory synaptic transmission. (a) sEPSCs in the CAI of GLSI hets and WT littermates. Representative traces of sEPCS (al) recorded from WT (left) and GLSI hets (right) are shown. The frequency (a2) but not average amplitude (a3) of sEPSCs was reduced in GLSI hets compared with WT. WT>GLSI hets, *p < 0.05. Data were collected from $12 \mathrm{WT}$ slices obtained from seven mice and $10 \mathrm{GLSI}$ het slices from five mice; numbers in parentheses indicate numbers of cells recorded. (b) sEPSCs in the anterior cingulate cortex of GLSI hets and WT littermates. Representative traces of sEPSCs (b I) recorded from WT (left) and GLSI hets (right). There were no differences in frequency (b2) or amplitude (b3). Data were collected from six slices obtained from three WT mice and six slices from three GLSI het mice. (c) The input-output curve of fEPSP slope $(\mathrm{V} / \mathrm{sec})$ vs stimulus intensity at Schaeffer collateral-CAI synapses in HIPP slices showed decreased synaptic strength in GLSI hets. $W T>G L S I$ hets, $* p<0.05$. Data were collected from six WT and six GLS I het mice; numbers in parentheses indicate numbers of slices recorded. The curves drawn were generated using a fourth order polynomial curve fit.

Figure 5a3), indicating that HIPP-dependent encoding, storage, and/or retrieval of contextual information was diminished in GLS1 hets.
As impaired context learning in the fear-conditioning task could be indicative of more general memory deficits, we tested HIPP-dependent memory in the Morris Water Maze task. Visible platform training is an index of reference memory, and the time to reach the platform is an indirect measure of the animal's motor function and motivation to engage in the task (Morris, 1984). The experiment included 15 mice. Time to reach the platform during visible-platform training was similar between GLS1 hets and WT mice ( $t$-test; $p>0.1$; data not shown). Performance in hiddenplatform training and in the probe trials is an indication of spatial learning and long-term memory. Data were analyzed with repeated-measure ANOVA, with genotype as the between-subject factor and training day as the withinsubject factor. Both genotypes showed similar improvement over training days in the hidden-platform procedure (Figure 5b1; training day main effect $\mathrm{F}(7,84)=6.76$, $p<0.01$, no effect of genotype $(\mathrm{F}(1,12)<1$, NS) and no genotype $\times$ training day interaction $(F(7,84)<1, N S)$. Data from each probe trial were analyzed with repeated-measure ANOVAs, with genotype as the between-subject factor and quadrant as the within-subject factor. Memory of platform location was intact in WT and in GLS1 hets, as shown by the higher percent of time spent by mice of both genotypes in the target quadrant (quadrant 1) compared with other quadrants on probe trial 1 (Figure 5b2; main effect of quadrant $\mathrm{F}(3,39)=10.43 p<0.001$, no effect of genotype $\mathrm{F}(1,13)=1.28, p>0.1$, no quadrant $\times$ genotype interaction $\mathrm{F}(3,39)<1$, NS) and 7 days later, on probe trial 2 (Figure 5b3; main effect of quadrant $\mathrm{F}(3,33)=10.75 p<0.001$, no effect of genotype $\mathrm{F}(1,11)=2.22, p>0.1$, no quadrant $\times$ genotype interaction $\mathrm{F}(3,33)<1, \mathrm{NS})$.

Mnemonic function was tested further in the novel object recognition task. The experiment included 21 mice. Data from the sample phase were analyzed with a two-way ANOVA, with genotype and object as main factors. Mice of neither genotype showed preference for either of the objects used (two-way ANOVA: no main effect of object $\mathrm{F}(1,19)<1$, NS, no main effect of genotype $F(1,19)<1$, NS, no genotype $\times$ object interaction $\mathrm{F}(1,19)=1.98, p>0.1$, data not shown). Data from the retention phase (Figure $5 \mathrm{c}$ ) were analyzed with a two-way ANOVA, with genotype and novelty as main factors. Both WT and GLS1 het mice spent significantly longer exploring the novel object compared with the familiar object (main effect of novelty, $\mathrm{F}(1,19)=9.47, \quad p<0.01$, no main effect of genotype $\mathrm{F}(1,19)<1$, NS, no novelty $\times$ genotype interaction $\mathrm{F}(1,19)<1$, NS). Overall, contextual fear conditioning seemed to be the mnemonic task most sensitive to physiological changes produced by the reduction in glutaminase activity.

\section{GLS1 hets Display a Blunted Frontal Cortical Response to Ketamine}

Guided by findings of exaggerated FC activation following the systemic administration of ketamine in patients with SCZ (Breier et al, 1997; Holcomb et al, 2005) and animal models (Duncan et al, 1999; Miyamoto et al, 2000), we assessed ketamine-induced activation of rCBV in the FC and HIPP, using a ketamine dose $(30 \mathrm{mg} / \mathrm{kg})$ earlier tested in mouse imaging studies (Duncan et al, 1999; 

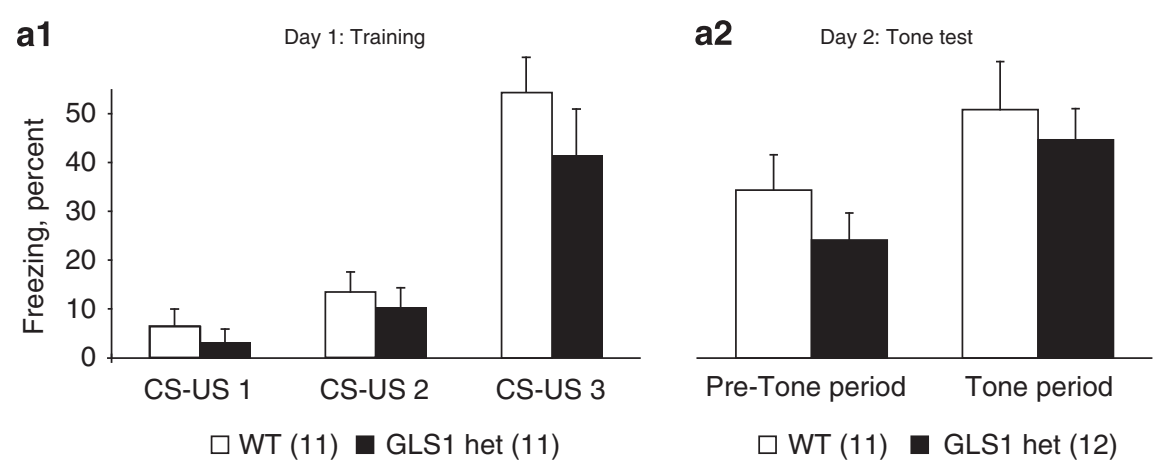

a3 Day 3: Context test

$\square \mathrm{WT}(11) \square \mathrm{GLS} 1$ het (11)

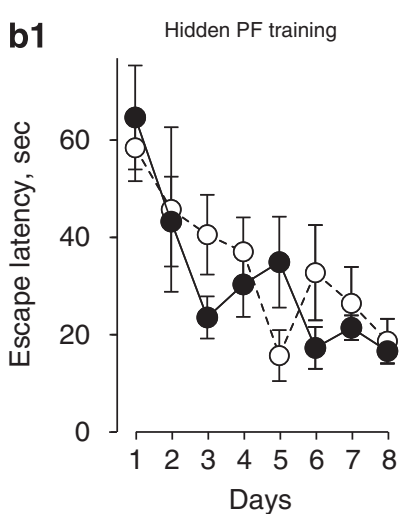

- - - - WT (6) -—- GLS1 het (9) b2 Day 8: Probe

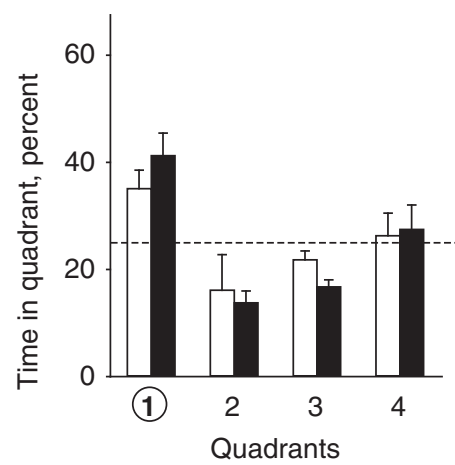

$\square \mathrm{WT}(6)$ b3 Day 15: Probe 2

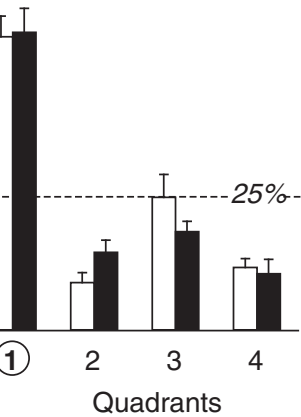

GLS1 het (8)

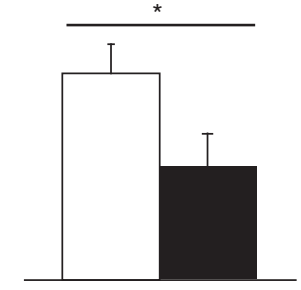

Context

$\square$ WT (14) घ GLS1 het (11)

Figure 5 GLSI hets show reduced contextual fear conditioning, but are not impaired in other memory tasks. (a) During fear conditioning on day I, both GLSI hets and WT littermates showed increased freezing with repeated CS-US pairings (al) On day 2, both genotypes froze significantly more during the tone period than during the pre-tone period (a2) However, on day 3, GLSI hets froze significantly less in the context test. * WT $>$ GLSI hets, $p<0.05$. (b) In the Morris Water Maze task during hidden platform (PF) training, both genotypes displayed improved performance (ie, decreased latencies) over successive training days (bI). On day 8, immediately after the last session of hidden PF training (b2), and on day I5, I week post-hidden PF training (b3), both genotypes spent significantly more time in the target quadrant (I). (c) In the Object Recognition Test, both GLSI hets and WT littermates spent more time exploring the novel object than the familiar one; there were no genotypic differences.

Miyamoto et al, 2000). The experiment included 16 mice. Data were analyzed with a repeated-measure ANOVA, with genotype as the between-subject factor and scan number as the within-subject factor. Analysis of rCBV in the FC at baseline (pre) and during the three post-ketamine scans (posts 1,2 , and 3) showed a significant main effect of genotype $(\mathrm{F}(1,12)=6.51, p<0.05)$ and a genotype $\times$ scan interaction $(\mathrm{F}(3,10)=8.75, p<0.005)$. Post hoc analysis showed lower rCBV in GLS1 hets specific to the FC during the post 2 and post 3 scans (all $p$-values $<0.05$; Figure 6 , upper panel). In the HIPP, ketamine increased $\mathrm{rCBV}$ independent of genotype (main effect of scan, $\mathrm{F}(3,10)=4.3, p<0.05$ ) (Figure 6, lower panel). These data indicate that in GLS1 hets the FC of is less sensitive to the stimulant effects of this drug, at the dose used.

\section{GLS1 hets Show a Diminished Response to Amphetamine}

The effects of amphetamine administration on locomotor activity and on striatal DA levels in animals are commonly used to evaluate the relevance of manipulations in rodent models to the positive symptoms of SCZ (Jentsch et al, 1998; Moore et al, 2006; Paterlini et al, 2005). Moreover, amphetamine-induced locomotion and striatal DA efflux are blunted by blockade of glutamate transmission at non-NMDA glutamate receptors (David et al, 2004;
Moghaddam and Bolinao, 1994). Guided by these studies, we measured changes in locomotor activity and striatal DA efflux after systemic administration of amphetamine. The behavioral experiment included 30 mice, randomly assigned to receive amphetamine $(2.0 \mathrm{mg} / \mathrm{kg}$, i.p.) or saline. Data were analyzed with a repeated-measure two-way ANOVA, with genotype and drug as the between-subject factors and time as the within-subject factor. There were no genotypic differences in baseline locomotor activity, (repeated-measure two-way ANOVA on pre-amphetamine data, all $p$-values $>0.1$; Figure $7 \mathrm{a}$ ), replicating our earlier findings depicted in Figure 2a. After amphetamine administration, WT mice showed an increase in locomotion that persisted for the duration of the test period $(90 \mathrm{~min})$. In contrast, GLS1 hets were insensitive to the effects of amphetamine at this dose, and did not differ from saline-treated GLS1 hets or saline-treated WT mice (main effect of genotype $\mathrm{F}(1,26)=6.88, p<0.05$, main effect of drug $\mathrm{F}(1,26)=8.09$, $p<0.01$, genotype $\times$ drug interaction $\mathrm{F}(1,26)=4.69$, $p<0.05$, time $\times$ drug interaction $\mathrm{F}(8,19)=4.58, p<0.005)$. Post hoc tests on ambulatory distance values averaged across the $90 \mathrm{~min}$ post-amphetamine period showed significant differences $(p$-values $<0.05)$ between the WT-amphetamine group and each of the other three groups (WT-saline, GLS1 het-saline, and GLS1 het-amphetamine). 
In a separate group of 12 mice per genotype, in vivo microdialysis was used to assess the increase in DA efflux in the striatum after the same dose of amphetamine used in the behavioral study $(2.0 \mathrm{mg} / \mathrm{kg}$, i.p.). The distribution of probe placements was contained within the anterior medial and central caudate and the nucleus accumbens, and did not differ between genotypes (Supplementary Information, Figure S2). As mice were tested in matched pairs (see Methods), and the genotypes differed in the normality of distribution of the post-amphetamine data, the Wilcoxon signed ranks test for related pairs was used to compare genotypes. Baseline recovery of DA did not differ in GLS1 hets (Wilcoxon $\mathrm{Z}=1.6$, two-tailed $p=0.1$; Figure $7 \mathrm{~b} 1$ ); moreover, across both genotypes, the maximum fold change
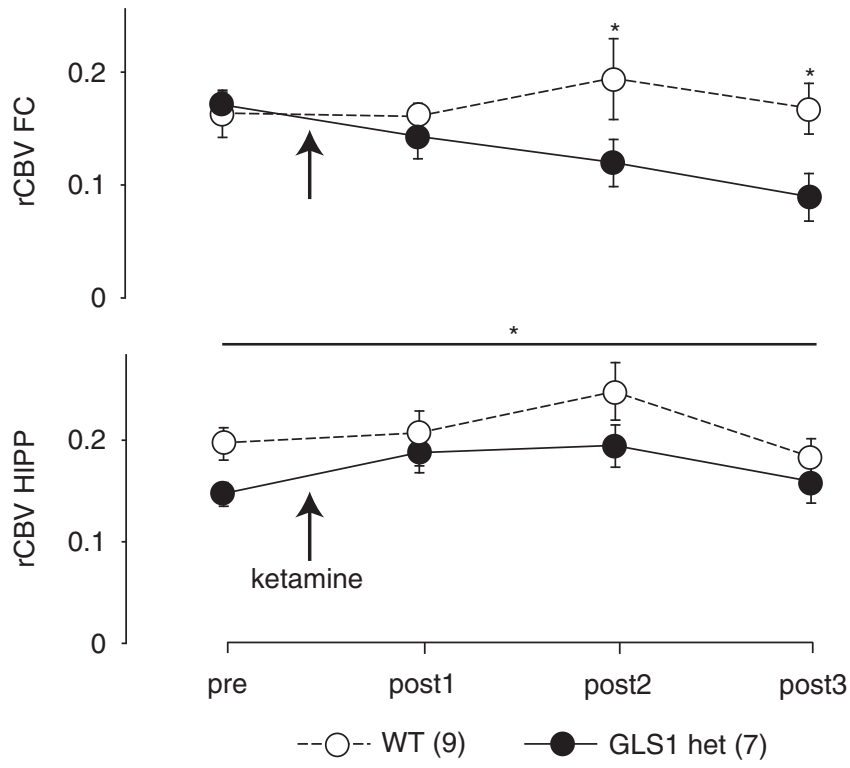

Figure 6 Reduced cortical rCBV response after ketamine in GLSI hets. rCBV in the FC (upper) and HIPP (lower) of GLSI het and WT mice before (pre) and during three scans after $30 \mathrm{mg} / \mathrm{kg}$ ketamine (arrow) administration (post I, post 2 and post 3). rCBV was reduced in GLSI hets during scans post 2 and post 3. WT $>$ GLSI hets, $*$ p $<0.05$. The FC of GLSI hets was not responsive to the stimulating effects of ketamine, which increased rCBV in the FC of WT mice. In the HIPP, both GLSI hets and WTs showed enhanced rCBV during scans post 1 and post 2 after ketamine administration $* p<0.05$. in DA efflux did not correlate with baseline DA levels (Spearman's $\rho<0.1, p>0.6$ ). GLS 1 hets showed a significant reduction in the amphetamine-induced increase in striatal DA efflux, expressed as the maximum fold change (Wilcoxon $\mathrm{Z}=-2.0$, two-tailed $p<0.05$; Figure $7 \mathrm{~b} 2$ ). Thus, GLS1 hets were less responsive to amphetamine challenge.

\section{GLS1 hets Display Clozapine-Like Potentiation of Latent Inhibition}

As our studies show that GLS1 hets display reduced sensitivity to pro-psychotic drugs, we asked whether the mice would show an antipsychotic-like profile in the latentinhibition (LI) test. Antipsychotic and pro-cognitive drugs enhance, or potentiate, LI when given on their own (Moser et al, 2000; Weiner et al, 1997). Using a conditioned freezing paradigm that enables the detection of antipsychotic druglike LI potentiation (Yee et al, 2006), we looked specifically at potentiated LI, asking whether GLS1 hets would be similar to clozapine-treated WT mice, and furthermore whether administering clozapine to GLS1 hets would affect LI. To enable the detection of LI potentiation in clozapine-treated animals, the experimental parameters were set so that there was no LI in WT animals. The experiment included 67 mice, randomly assigned to receive clozapine $(1.5 \mathrm{mg} / \mathrm{kg}$, i.p.) or saline. Data from the tone test day were analyzed with two separate three-way ANOVA, with genotype, drug, and preexposure as the between-subject factors, and pre-tone freezing and freezing ratio as the dependent variables. We found in the $3 \mathrm{~min}$ before CS onset that freezing frequency was low ( $<50 \%$ in all groups) and showed no genotypic difference (no main effects or interaction, all $p$-values $>0.1$, Figure 8a). Freezing ratios represent freezing values post tone onset normalized to freezing values pre-tone for each mouse. As expected, in WT mice there was no difference between pre-exposed (PE) and non-preexposed (NPE) animals treated with saline (ie, no LI), whereas clozapine led to the potentiation of LI as described earlier (Lipina et al, 2005). LI was present in both saline- and clozapine-treated GLS1 hets (Figure 8b; main effect of pre-exposure $\mathrm{F}(1,59)=17.1, p<0.001$, pre-exposure $\times$ genotype interaction $\mathrm{F}(1,59)=5.29, p<0.05$; no other main effects or interactions, all $p$-values $>0.5)$. Post hoc LSD comparisons between $\mathrm{PE}$ and NPE groups in each drug/genotype
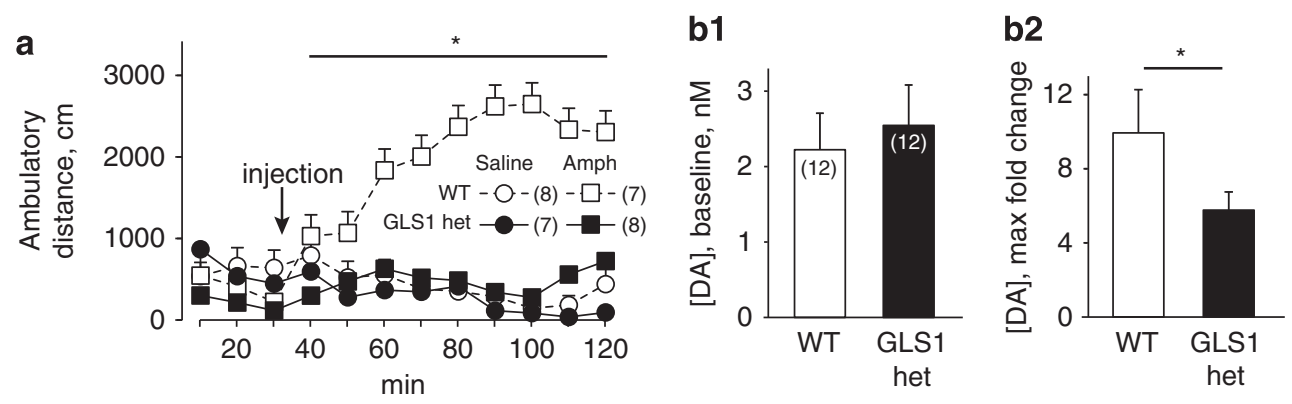

Figure 7 Attenuated behavioral and neurochemical response to amphetamine in GLSI hets. (a) Ambulatory distance was measured before and after i.p. injection of amphetamine (Amph; $2 \mathrm{mg} / \mathrm{kg}$ ) or saline (arrow). There were no baseline genotypic differences in activity. After amphetamine administration, WT mice showed a robust increase in activity, whereas GLSI hets, as well as saline-treated mice of both genotypes, showed no increase in activity. *WTAmph > GLSI het-Amph, GLSI het-saline, WT-saline, $p<0.05$. (b) Microdialysis measurement of baseline DA recovery showed no genotypic differences (b l). Following systemic amphetamine $(2 \mathrm{mg} / \mathrm{kg})$, the maximum amphetamine-induced increase in DA efflux in GLSI hets was reduced relative to their WT littermates. WT-Amph $>$ GLSI-Amph, *p $<0.05$ (b2). 

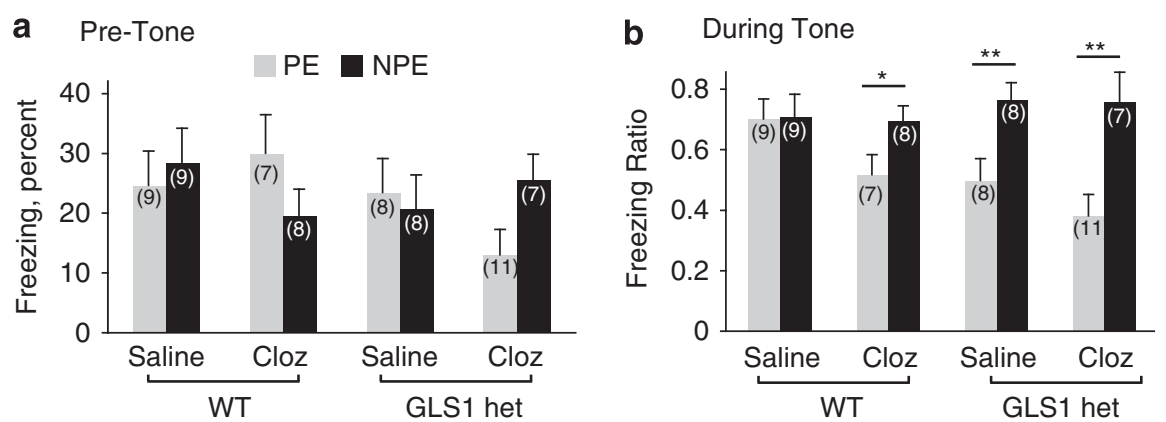

Figure 8 GLSI hets display clozapine-like potentiation of latent inhibition. (a) Mean percent freezing of pre-exposed (PE) and non-pre-exposed (NPE) saline- and clozapine-treated WT and GLSI het mice during the pre-tone period on the test day. Similar low freezing levels were observed in all groups. (b) Freezing ratios during the tone test. Latent inhibition, that is, a lower suppression ratio in PE as compared with NPE mice, was observed in clozapinetreated WT mice and in saline- and clozapine-treated GLSI hets, but not in saline-treated WT mice. NPE $>$ PE, ${ }^{*} p<0.05, * * P<0.0$ I.

condition confirmed the emergence of LI in clozapinetreated WTs $(p<0.05)$, saline-treated GLS1 hets $(p<0.01)$, and clozapine-treated GLS1 hets $(p<0.01)$, but not in salinetreated WT mice $(p>0.5)$. LSD comparisons between PE groups in the different genotype/drug conditions showed a difference approaching significance between saline-treated PE WT mice and clozapine-treated PE WT mice $(p=.0718)$, between saline-treated preexposed WT mice and salinetreated PE GLS1 hets $(p=.0536)$ and a significant difference between saline-treated PE WT mice and clozapine-treated PE GLS1 hets $(p<0.005)$. Thus, GLS1 hets display clozapinelike potentiation of LI, and the effect is due to reduced suppression in the PE groups.

\section{DISCUSSION}

We asked whether a heterozygous reduction in GLS1 in mice affecting the glutamate-glutamine cycle would impact baseline behavioral function. Motivated by the considerable evidence implicating abnormalities in glutamate transmission in the pathophysiology of SCZ symptoms, we asked further whether GLS1 hets would manifest phenotypes seen in mouse models of SCZ. We found that although GLS1 het mice displayed a subtle reduction in cortical and HIPP glutamate, their baseline behavior was mostly normal. However, functional imaging showed a reduction in HIPP $\mathrm{rCBV}$, inverse to recent findings in clinical and prodromal SCZ populations. GLS1 hets showed attenuated ketamineinduced frontal cortical activation, blunted amphetamineinduced locomotor stimulation and DA release, and clozapine-like potentiation of LI, all opposite in direction to the phenotypes seen in mouse models of SCZ, and consistent with phenotypes associated with antipsychotic drug treatment. Taken together, the imaging and behavioral data support the relevance of glutamatergic transmission to SCZ, and in particular to the positive symptoms of this disorder. The data further suggest that glutaminase inhibition may prove therapeutic in SCZ.

\section{Constitutive Reduction in GLS1 Significantly Impacts Glutamate Function}

Although there has been a consensus that the glutamateglutamine cycle generates the majority of neurotransmitter glutamate (Hertz, 2004), this has been questioned in recent synaptic studies (Kam and Nicoll, 2007). Indeed, three glutamine-independent cycles for glutamate trafficking involving tricarboxylic acid cycle intermediates have been identified (Maciejewski and Rothman, 2008), as well as the expression of the glutamate reuptake transporter GLT1a in neurons (Chen et al, 2004). Nonetheless, we found that GLS1 hets show reductions in glutamate (the GLS1 product) and elevations in glutamine (the glutaminase substrate), and a global reduction in glutamate-glutamine ratios, showing that haploinsufficiency in GLS1 yields a neurochemical phenotype likely to impact glutamate neurotransmission. In brain slice recordings, we found that although spontaneous activity was unaffected in anterior cingulate cortex, both spontaneous and evoked synaptic input was reduced in CA1, pointing to regional heterogeneity in systems maintaining glutamate synaptic homeostasis. Consistent with this, earlier studies have shown that inhibiting glial glutamine production with fluoroacetate differentially affects synaptic transmission in HIPP subregions; 10-fold more fluoroacetate was required to inhibit excitatory transmission in the dentate gyrus than in CA1 (Keyser and Pellmar, 1997). Possibly, the HIPP regional specificity in GLS1 hets could be due to higher levels of GLS1 expression (Lein et al, 2007; Najlerahim et al, 1990), and thus perhaps greater dependence on glutamate recycling through glutaminase in CA1 compared with other brain regions.

\section{GLS1 hets Display Largely Normal Behavior}

Abnormal glutamate transmission has been implicated not only in SCZ, but also in a range of neuropsychiatric disorders including anxiety, depression, and drug addiction. We, therefore, assumed that even a small reduction in brain glutamate levels would have significant behavioral impact. We used a wide-ranging battery of behavioral tests to detect possible alterations in baseline behavior, but found GLS1 hets were remarkably normal in every measure, except for context-dependent fear conditioning.

Several hypotheses may account for the ordinariness of the mice: first, the behavioral normalcy and the regional selectivity of the effects that we did observe, could be due to the selective expression pattern of the GLS1 protein 
in regions that are involved in SCZ-related pathology, in particular the CA1 and CA3 subregions of the HIPP (Lein et al, 2007; Najlerahim et al, 1990). Second, as GLS1 haploinsufficiency is present in GLS1 hets throughout development, compensatory processes in non-glutamatergic neurotransmitter systems may have been engendered, reducing the impact of the deficiency in adulthood; however, significant alterations in other neurotransmitter systems would likely have been associated with a behavioral phenotype. Third, it is possible that flawed glutaminase function (and glutamatergic transmission) may be sufficient for flawless behavioral performance in most behavioral assays - some tasks may be more vulnerable to a mild decrease in glutamate transmission than others. In GLS1 hets, HIPP-dependent contextual learning in the fear conditioning paradigm was selectively diminished. Interestingly, pharmacological interference with the actions of other molecules that participate in the glutamate-glutamine cycle has been reported to produce HIPP-specific behavioral abnormalities (Calas et al, 2008; Carney et al, 1991; Carney et al, 2002; Gibbs et al, 1996). As GLS1 hets did not show general cognitive deficits, GLS1 haploinsufficiency seems to affect contextual learning selectively.

\section{Hippocampal Specificity and Relevance to SCZ}

Although GLS1 expression, glutaminase activity, and glutamate levels were reduced throughout the brain of GLS1 hets, baseline rCBV was reduced selectively in two specific subregions of the HIPP, the CA1 subfield and the SUB. Our recent clinical findings (Schobel et al, 2009) showing increased CBV in the CA1 and SUB of SCZ patients and high-risk individuals, are in accord with extensive evidence implicating HIPP dysfunction in SCZ, and with a growing number of studies-imaging and post-mortem - that point to elevated baseline HIPP activity in the disorder (Heckers, 2001; Malaspina et al, 2004; Medoff et al, 2001). The present imaging and electrophysiological studies in GLS1 hets point to reduced HIPP activity in the same subregions. Reduced HIPP activity is unlikely to result from histological defects, as even in GLS1 null mice there were no such defects in the hippocampus (Masson et al, 2006), and in GLS1 hets we found no evident cell loss (Lee and Rayport, unpublished observations). Rather, these observations suggest that the pathological processes that lead to increased metabolic activity in the CA1 and SUB in SCZ may be absent in the same subregions in GLS1 hets, and, by extension, that decreased presynaptic glutamate may afford protection from these processes.

In the present set of experiments, impaired contextual learning stands out as the only baseline behavioral measure that was affected. The HIPP plays a central role in the processing and retrieval of contextual information (Honey and Good, 1993; Jarrard, 1995; Kim and Fanselow, 1992). Computational models and empirical studies suggest that the CA3 subregion has a unique neuronal architecture, which makes it especially suited for the processing of multimodal information inherent to contextual learning, whereas the CA1 subregion plays an important role in the consolidation of contextual information (Daumas et al, 2005; Nakazawa et al, 2002). The absence of deficits in the Morris Water Maze and Novel Object Recognition tests could be due to the fact that these memory tasks require normal function of cortical and cortico-hippocampal projections other than the Schaeffer collateral projection (Brown and Aggleton, 2001; Remondes and Schuman, 2004).

As we observed no deficits in the Morris Water Maze and Novel Object Recognition tests, we hypothesize that the deficit in contextual fear conditioning in GLS1 hets produces a rather specific deficit in the ability to acquire or attribute salience to contextual cues. Abnormal processing of contextual information has been observed in SCZ (Boyer et al, 2007; Hemsley, 2005), as has inability to inhibit contextually irrelevant information (Titone et al, 2000). Furthermore, misattribution of salience to neutral stimuli (such as contextual cues) has been explicitly linked to delusional thinking (Holt et al, 2006; Jensen and Kapur 2009; Roiser et al, 2009) and HIPP hyperactivity (Seiferth et al, 2008). These observations, taken together with our findings in other models of SCZ-related symptoms, support the idea that the deficit in context learning observed in GLS1 hets is not indicative of SCZ-like cognitive deficits, but could in fact be regarded as a protective process. Further studies will be needed to address the relationship between context learning and salience attribution in GLS1 hets.

\section{Attenuated Response to Ketamine}

An increase in cortical rCBV in response to the propsychotic drug, ketamine, was observed in WT mice, but not in GLS1 hets. Studies in healthy humans and rodents show that acute administration of NMDA receptor blockers increases activity in corticolimbic regions (Gozzi et al, 2008; Littlewood et al, 2006). In patients with SCZ, the response to ketamine is exaggerated specifically in cortical regions, and this correlates with the severity of psychotic symptoms (Holcomb et al, 2005; Soyka et al, 2005; Tamminga et al, 2003). The hypo-glutamatergic profile of GLS1 hets provides a likely explanation for their insensitivity to ketamine: the pro-psychotic effects of ketamine in humans and animals are hypothesized to result from hyperactivity of glutamatergic pyramidal neurons and abnormal glutamate release in the cortex (Holcomb et al, 2005; Moghaddam et al, 1997; Olney et al, 1999). A recent rat rCBV study showed that the hyper-metabolic effects of PCP are prevented by preadministration of agents that reduce glutamate release (Gozzi et al, 2008). Thus, GLS1 hets may be protected from the effects of ketamine by their diminished ability to release excessive amounts of glutamate. It should be kept in mind that although the dose of ketamine used in this study $(30 \mathrm{mg} / \mathrm{kg}$ ) was based on the earlier behavioral and ex vivo imaging studies, there may have been anesthesia-related effects.

\section{Attenuated Response to Amphetamine}

Amphetamine induces in patients with SCZ an exacerbation in psychotic symptoms, and an exaggerated increase in synaptic DA release in the striatum (Laruelle et al, 1996; Martinez et al, 2003). Similarly, increases in amphetamineevoked motor activity and striatal DA efflux are seen in several rodent models that mimic pathological processes in SCZ (Jentsch et al, 1998 ; Moore et al, 2006; Paterlini et al, 2005). DA-glutamate interactions are complex (David et al, 
2004; Javitt, 2007). Under conditions of NMDA receptor blockade, locomotion can be uncoupled from DA transmission (Nilsson et al, 2001), as exemplified by findings of enhanced amphetamine-induced striatal DA efflux and locomotion after repeated administration of the NMDA antagonist phencyclidine (Javitt, 2007; Jentsch et al, 2003). However, a number of studies have shown that both acute amphetamine-induced locomotion and striatal DA efflux are reduced by non-NMDA glutamate receptor antagonists (David et al, 2004; Moghaddam and Bolinao, 1994), and that manipulations that enhance extracellular glutamate levels induce an increase in DA transmission (Karlsson et al, 2008). One possible explanation for this dissociation is that selective NMDA receptor blockade produces an increase in cortical glutamate efflux (Moghaddam and Adams, 1998), which leads to an enhanced dopaminergic response. This is further supported by the demonstrated antipsychotic efficacy (Patil et al, 2007) in a phase 2 clinical trial of a metabotropic glutamate receptor $2 / 3$ agonist, which acts through presynaptic suppression of cortical glutamate release.

In GLS1 hets, amphetamine-induced hyperlocomotion and amphetamine-evoked DA release were significantly reduced. The finding of a decreased response of the mesostriatal DA system to amphetamine in GLS1 hets is especially intriguing when considered in the context of HIPP hypofunction. The HIPP normally provides a novelty signal to DA neurons (Lisman and Grace, 2005). Hippocampal hyperactivity in the MAM E17 rat, a well-validated animal model of SCZ (Grace et al, 2007; Lodge and Grace, 2007; Moore et al, 2006), enhances DA neuron activity, presumably by increasing the numbers of DA neurons that may be activated by other salience signals (Grace et al, 2007). Conversely, a hypoactive HIPP in GLS1 hets may reduce the numbers of DA neurons that would be activated by salience signals, and possibly protect against the stimulatory effects of amphetamine on excessive DA neuron output.

Although the $2 \mathrm{mg} / \mathrm{kg}$ amphetamine dose did not stimulate locomotion in GLS1 hets, it did evoke DA release. This apparent discrepancy could be due to non-dopaminergic mechanisms, which may participate in eliciting the behavioral response to amphetamine (Paterlini et al, 2005; Rorick-Kehn et al, 2007), or from differential contributions of pre- and post-synaptic components of the DA system to changes in striatal DA concentration as measured with microdialysis and abnormal motor activity (Matsuzaki and Tohyama, 2007). In any case, these results indicate that a reduction in glutaminase results in dopaminergic system that is less responsive to amphetamine, possibly due to a limit on glutamate transmission at AMPA or kainate glutamate receptors. Taken together with the reduced hemodynamic response to ketamine, the reduced responsiveness of the DA system to amphetamine in GLS1 hets supports the hypothesis that limiting glutaminase activity confers resilience to pro-psychotic challenges.

\section{Glutaminase Deficiency and the Glutamate Theory of SCZ: Treatment Implications}

LI is one of the best documented cross-species manifestations of attentional selectivity in associative learning
(Weiner, 2003), and is shown when animals that receive repeated non-reinforced pre-exposure to the to-be-conditioned CS exhibit poorer conditioning than non-preexposed animals. The disruption of LI in humans and rodents after pharmacological, genetic, or neurodevelopmental manipulations is considered to model the inability of patients with SCZ to ignore irrelevant stimuli. Conversely, antipsychotic and pro-cognitive drugs enhance, or potentiate, LI when given on their own (Moser et al, 2000; Weiner et al, 1997). In this study, we found potentiated LI in clozapine-treated WT mice and in saline- or clozapinetreated GLS1 hets. The potentiation of LI is a widely documented consequence of typical, atypical and novel antipsychotic drug treatments, and is commonly used as a screening test for compounds that are potentially therapeutic in SCZ (Black et al, 2009; Dunn et al, 1993; Weiner et al, 1997). Importantly, treatments that reduce glutamate signaling at the NMDA receptor, such as the NMDA receptor blocker MK801, potentiate LI. However, an important aspect of the latter effect is its reversibility by clozapine and other atypical and putative antipsychotic drugs; thus, MK-801-treated animals pre-treated with clozapine displayed normally absent LI (Gaisler-Salomon and Weiner, 2003; Lipina et al, 2005). Here, clozapine had the same effect on WT animals as on GLS1 hets. This implies that glutaminase deficiency does not mimic NMDA receptor blockade in the LI model, but rather the actions of clozapine and other antipsychotic drugs.

In agreement with the potentiated LI phenotype, the attenuated response to amphetamine and ketamine observed in GLS1 hets is indicative of an antipsychotic druglike profile (Gozzi et al, 2008; Ichikawa and Meltzer, 1992). Although variations in the GLS1 gene were not found to be associated with SCZ (Maeshima et al, 2007; Zhang et al, 2005), post-mortem studies show increased GLS1 expression (Bruneau et al, 2005) and activity (Gluck et al, 2002) in SCZ, and antipsychotic drugs have been reported to inhibit glutaminase (Sherman et al, 1988). Taken together with our observations, these findings argue for glutaminase inhibition as a potential treatment in SCZ. It should be noted that the studies described here cannot address the question of whether more subtle or more substantial reductions in glutaminase activity would lead to similar phenotypes; future studies, perhaps with pharmacological compounds that reduce glutaminase activity, will hopefully be able to provide a dose-response curve.

As GLS1 hets are haploinsufficient throughout their development, we cannot rule out the possibility that the phenotypes observed are due to compensatory effects downstream of the glutamate-glutamine cycle. However, although secondary effects are important and occur after any genetic or pharmacological manipulation, it is important to note that GLS1 expression and glutaminase activity levels were significantly reduced in adult GLS1 hets, and that several of the phenotypes we observed have been reported earlier in animals with pharmacologically induced reductions in presynaptic glutamatergic transmission. For example, mice treated with agents that reduce glutamate release show reduced cortical activation in response to NMDA receptor blockade (Gozzi et al, 2008) and reduced amphetamine-induced locomotor activity (Arban et al, 2005). Thus, reductions in glutaminase activity and in 
glutamate transmission provide likely mechanisms for the observed phenotypes in GLS1 hets.

In sum, our findings of HIPP hypoactivity, insensitivity to pro-psychotic agents and an antipsychotic-like profile in the LI test, indicate that GLS1 haploinsufficiency does not result in SCZ-like phenotypes in mice, but rather in a profile that could be described as SCZ-resilient, one that may be of particular relevance for the pharmacotherapy of positive symptoms. Although it has been shown earlier that a restricted genetic manipulation of glycine transporter 1 in forebrain neurons could produce a mouse with a SCZresilient profile (Yee et al, 2006), here we have shown that a wide-spread genetic manipulation has a relatively HIPPselective effect that is associated with SCZ resilience, making glutaminase a promising pharmacotherapeutic target. The fact that both glutaminase activity and glutamate levels are reduced in adulthood suggests that a reduction in glutaminase, and the ensuing decrease in glutamate levels, are plausible explanations for the phenotypes observed in GLS1 hets, and argues against the possibility that these effects are due to neurodevelopmental alterations unrelated to GLS1 or to glutamate neurotransmission. These results inform and clarify a broader mechanistic interpretation of SCZ, identifying a constellation of key features of SCZ pathology, namely HIPP hyperfunction, aberrant cortical activity, and abnormalities in DA neurotransmission, and argue for further investigation of glutaminase as a novel therapeutic target for the treatment of SCZ.

\section{ACKNOWLEDGEMENTS}

We thank Shonagh O'Leary Moore for help with the MRS tissue analysis, Kenneth Hess and Fan Hau for mouse imaging, Karin Krueger, Sara Steinfeld and Alexei Chemiakine for expert performance of the surgical procedures and neurochemical analyses for the microdialysis studies, and Xiaoqiao Zhu for assisting with behavioral studies. We are grateful to Ina Weiner for critical discussion. The behavioral experiments utilized the facilities of the Rodent Models Neurobehavioral Analysis Core of the Lieber Center for Schizophrenia Research at Columbia University and the New York State Psychiatric Institute (Holly M. Moore, Director). This work was supported by the NIMH (P50 MH066171 to SR and HM, R01 MH068073 to PB), NIDA (K02 DA000356 to SR, T32 DA016224 to IGS, R01 DA016373 to MPG), NIA (R01 AG025161 to SAS), NINDS (R01 NS049442 to OA), the Joe Young Sr. Research Fund in Psychiatry (MPG), the Wayne State Anesthesiology Research Fund (MPG), and the Rothschild Foundation (IGS).

\section{DISCLOSURE/CONFLICT OF INTEREST}

René Hen receives compensation as a consultant for BrainCells Inc., PsychoGenics Inc., Astra Zeneca, and Lundbeck in relation to the generation of novel antidepressants. The other authors have no reported conflicts of interest to disclose.

\section{REFERENCES}

Arban R, Maraia G, Brackenborough K, Winyard L, Wilson A, Gerrard P et al (2005). Evaluation of the effects of lamotrigine, valproate and carbamazepine in a rodent model of mania. Behav Brain Res 158: 123-132.

Arguello PA, Gogos JA (2006). Modeling madness in mice: one piece at a time. Neuron 52: 179-196.

Belzung C, Misslin R, Vogel E, Dodd RH, Chapouthier G (1987). Anxiogenic effects of methyl-beta-carboline-3-carboxylate in a light/dark choice situation. Pharmacol Biochem Behav 28: 29-33.

Black MD, Varty GB, Arad M, Barak S, De Levie A, Boulay D et al (2009). Procognitive and antipsychotic efficacy of glycine transport 1 inhibitors (GlyT1) in acute and neurodevelopmental models of schizophrenia: latent inhibition studies in the rat. Psychopharmacology (Berl) 202: 385-396.

Boyer P, Phillips J, Rousseau F, Ilivitsky S (2007). Hippocampal abnormalities and memory deficits: new evidence of a strong pathophysiological link in schizophrenia. Brain Res Rev 54: 92-112.

Braff DL, Geyer MA, Swerdlow NR (2001). Human studies of prepulse inhibition of startle: normal subjects, patient groups, and pharmacological studies. Psychopharmacology (Berl) 156: 234-258.

Breier A, Malhotra AK, Pinals DA, Weisenfeld NI, Pickar D (1997). Association of ketamine-induced psychosis with focal activation of the prefrontal cortex in healthy volunteers. Am J Psychiatry 154: 805-811.

Brown MW, Aggleton JP (2001). Recognition memory: what are the roles of the perirhinal cortex and hippocampus? Nat Rev Neurosci 2: 51-61.

Bruneau EG, McCullumsmith RE, Haroutunian V, Davis KL, Meador-Woodruff JH (2005). Increased expression of glutaminase and glutamine synthetase mRNA in the thalamus in schizophrenia. Schizophr Res 75: 27-34.

Calas A, Richard O, Meme S, Beloeil J, Doan B, Gefflaut T et al (2008). Chronic exposure to glufosinate-ammonium induces spatial memory impairments, hippocampal MRI modifications and glutamine synthetase activation in mice. Neurotoxicology 29: 740-747.

Carney JM, Starke-Reed PE, Oliver CN, Landum RW, Cheng MS, Wu JF et al (1991). Reversal of age-related increase in brain protein oxidation, decrease in enzyme activity, and loss in temporal and spatial memory by chronic administration of the spin-trapping compound N-tert-butyl-alpha-phenylnitrone. Proc Natl Acad Sci USA 88: 3633-3636.

Carney R, Dardis C, Cullen WK, Felipo V, Anwyl R, Rowan MJ (2002). Early spatial memory deficit induced by 2,5-hexanedione in the rat. Toxicol Lett 128: 107-115.

Chaudhry FA, Reimer RJ, Edwards RH (2002). The glutamine commute: take the $\mathrm{N}$ line and transfer to the A. J Cell Biol 157: 349-355.

Chen W, Mahadomrongkul V, Berger UV, Bassan M, DeSilva T, Tanaka $\mathrm{K}$ et al (2004). The glutamate transporter GLT1a is expressed in excitatory axon terminals of mature hippocampal neurons. J Neurosci 24: 1136-1148.

Cohen J (1988). Statistical Power Analysis for the Behavioral Sciences 2nd (edn). L. Erlbaum Associates: Hillsdale, NJ.

Conjard A, Brun V, Martin M, Baverel G, Ferrier B (2002). Effect of starvation on glutamine ammoniagenesis and gluconeogenesis in isolated mouse kidney tubules. Biochem $J$ 368(Part 1): 301-308.

Curthoys NP, Lowry OH (1973). The distribution of glutaminase isoenzymes in the various structures of the nephron in normal, acidotic, and alkalotic rat kidney. J Biol Chem 248: 162-168.

Curthoys NP, Watford M (1995). Regulation of glutaminase activity and glutamine metabolism. Annu Rev Nutr 15: 133-159. 
Daumas S, Halley H, Frances B, Lassalle JM (2005). Encoding, consolidation, and retrieval of contextual memory: differential involvement of dorsal CA3 and CA1 hippocampal subregions. Learn Mem 12: 375-382.

David HN, Sissaoui K, Abraini JH (2004). Modulation of the locomotor responses induced by D1-like and D2-like dopamine receptor agonists and $\mathrm{D}$-amphetamine by NMDA and nonNMDA glutamate receptor agonists and antagonists in the core of the rat nucleus accumbens. Neuropharmacology 46: 179-191.

Dias R, Aggleton JP (2000). Effects of selective excitotoxic prefrontal lesions on acquisition of nonmatching- and matching-to-place in the T-maze in the rat: differential involvement of the prelimbic-infralimbic and anterior cingulate cortices in providing behavioural flexibility. Eur J Neurosci 12: 4457-4466.

Drew MR, Simpson EH, Kellendonk C, Herzberg WG, Lipatova O, Fairhurst $S$ et al (2007). Transient overexpression of striatal D2 receptors impairs operant motivation and interval timing. J Neurosci 27: 7731-7739.

Duncan GE, Miyamoto S, Leipzig JN, Lieberman JA (1999). Comparison of brain metabolic activity patterns induced by ketamine, MK-801 and amphetamine in rats: support for NMDA receptor involvement in responses to subanesthetic dose of ketamine. Brain Res 843: 171-183.

Dunn LA, Atwater GE, Kilts CD (1993). Effects of antipsychotic drugs on latent inhibition: sensitivity and specificity of an animal behavioral model of clinical drug action. Psychopharmacology (Berl) 112: 315-323.

Elvevag B, Brown GD, McCormack T, Vousden JI, Goldberg TE (2004). Identification of tone duration, line length, and letter position: an experimental approach to timing and working memory deficits in schizophrenia. J Abnorm Psychol 113: 509-521.

Elvevag B, McCormack T, Gilbert A, Brown GD, Weinberger DR, Goldberg TE (2003). Duration judgements in patients with schizophrenia. Psychol Med 33: 1249-1261.

Ennaceur A, Delacour J (1988). A new one-trial test for neurobiological studies of memory in rats. 1: Behavioral data. Behav Brain Res 31: 47-59.

Faul F, Erdfelder E, Lang AG, Buchner A (2007). G*Power 3: a flexible statistical power analysis program for the social, behavioral, and biomedical sciences. Behav Res Methods 39: 175-191.

Fitch RH, Threlkeld SW, McClure MM, Peiffer AM (2008). Use of a modified prepulse inhibition paradigm to assess complex auditory discrimination in rodents. Brain Res Bull 76: 1-7.

Gaisler-Salomon I, Weiner I (2003). Systemic administration of MK-801 produces an abnormally persistent latent inhibition which is reversed by clozapine but not haloperidol. Psychopharmacology (Berl) 166: 333-342.

Geyer MA, McIlwain KL, Paylor R (2002). Mouse genetic models for prepulse inhibition: an early review. Mol Psychiatry 7: 1039-1053.

Gibbs ME, O’Dowd BS, Hertz L, Robinson SR, Sedman GL, Ng KT (1996). Inhibition of glutamine synthetase activity prevents memory consolidation. Cogn Brain Res 4: 57-64.

Gluck MR, Thomas RG, Davis KL, Haroutunian V (2002). Implications for altered glutamate and GABA metabolism in the dorsolateral prefrontal cortex of aged schizophrenic patients. Am J Psychiatry 159: 1165-1173.

Gozzi A, Large CH, Schwarz A, Bertani S, Crestan V, Bifone A (2008). Differential effects of antipsychotic and glutamatergic agents on the phMRI response to phencyclidine. Neuropsychopharmacology 33: 1690-1703.

Grace AA, Floresco SB, Goto Y, Lodge DJ (2007). Regulation of firing of dopaminergic neurons and control of goal-directed behaviors. Trends Neurosci 30: 220-227.

Heckers S (2001). Neuroimaging studies of the hippocampus in schizophrenia. Hippocampus 11: 520-528.
Hemsley DR (2005). The development of a cognitive model of schizophrenia: placing it in context. Neurosci Biobehav Rev 29: 977-988.

Hertz L (2004). Intercellular metabolic compartmentation in the brain: past, present and future. Neurochem Int 45: 285-296.

Hertz L, Zielke HR (2004). Astrocytic control of glutamatergic activity: astrocytes as stars of the show. Trends Neurosci 27: 735-743.

Holcomb HH, Lahti AC, Medoff DR, Cullen T, Tamminga CA (2005). Effects of noncompetitive NMDA receptor blockade on anterior cingulate cerebral blood flow in volunteers with schizophrenia. Neuropsychopharmacology 30: 2275-2282.

Holt DJ, Titone D, Long LS, Goff DC, Cather C, Rauch SL et al (2006). The misattribution of salience in delusional patients with schizophrenia. Schizophr Res 83: 247-256.

Honey RC, Good M (1993). Selective hippocampal lesions abolish the contextual specificity of latent inhibition and conditioning. Behav Neurosci 107: 23-33.

Hunt MJ, Garcia R, Large CH, Kasicki S (2008). Modulation of high-frequency oscillations associated with NMDA receptor hypofunction in the rodent nucleus accumbens by lamotrigine. Prog Neuropsychopharmacol Biol Psychiatry 32: 1312-1319.

Ichikawa J, Meltzer HY (1992). The effect of chronic atypical antipsychotic drugs and haloperidol on amphetamine-induced dopamine release in vivo. Brain Res 574: 98-104.

Jarrard LE (1995). What does the hippocampus really do? Behav Brain Res 71: 1-10.

Javitt DC (2007). Glutamate and schizophrenia: phencyclidine, nmethyl-d-aspartate receptors, and dopamine-glutamate interactions. Int Rev Neurobiol 78: 69-108.

Javitt DC, Zukin SR (1991). Recent advances in the phencyclidine model of schizophrenia. Am J Psychiatry 148: 1301-1308.

Jensen J, Kapur S (2009). Salience and psychosis: moving from theory to practise. Psychol Med 39: 197-198 Epub 2008 Aug 12.

Jentsch JD, Olausson P, Moore H (2003). Animal models of psychosis. In: Soares JC, Gershon S (eds). Handbook of Medical Psychiatry. Marcel Dekker Inc:New York, Vol 20 pp 317-333.

Jentsch JD, Taylor JR, Roth RH (1998). Subchronic phencyclidine administration increases mesolimbic dopaminergic system responsivity and augments stress- and psychostimulant-induced hyperlocomotion. Neuropsychopharmacology 19: 105-113.

Kam K, Nicoll R (2007). Excitatory synaptic transmission persists independently of the glutamate-glutamine cycle. J Neurosci 27: 9192-9200.

Karlsson R, Heilig M, Holmes A (2008). Loss of glial glutamate and aspartate transporter (excitatory amino acid transporter 1) causes locomotor hyperactivity and exaggerated responses to psychotomimetics: rescue by haloperidol and metabotropic glutamate 2/3 agonist. Biol Psychiatry 64: 810-814.

Karlsson RM, Tanaka K, Saksida LM, Bussey TJ, Heilig M, Holmes A (2009). Assessment of glutamate transporter GLAST (EAAT1)deficient mice for phenotypes relevant to the negative and executive/cognitive symptoms of schizophrenia. Neuropsychopharmacology 34: 1578-1589.

Kellendonk C, Simpson EH, Polan HJ, Malleret G, Vronskaya S, Winiger $\mathrm{V}$ et al (2006). Transient and selective overexpression of dopamine D2 receptors in the striatum causes persistent abnormalities in prefrontal cortex functioning. Neuron 49: 603-615.

Keyser DO, Pellmar TC (1997). Regional differences in glial cell modulation of synaptic transmission. Hippocampus 7: 73-77.

Kim JJ, Fanselow MS (1992). Modality-specific retrograde amnesia of fear. Science 256: 675-677.

Large CH, Webster EL, Goff DC (2005). The potential role of lamotrigine in schizophrenia. Psychopharmacology (Berl) 181: 415-436.

Laruelle M, Abi-Dargham A, van Dyck CH, Gil R, D'Souza CD, Erdos J et al (1996). Single photon emission computerized 
tomography imaging of amphetamine-induced dopamine release in drug-free schizophrenic subjects. Proc Natl Acad Sci USA 93: 9235-9240.

LeDoux JE, Cicchetti P, Xagoraris A, Romanski LM (1990). The lateral amygdaloid nucleus: sensory interface of the amygdala in fear conditioning. J Neurosci 10: 1062-1069.

Lein ES, Hawrylycz MJ, Ao N, Ayres M, Bensinger A, Bernard A et al (2007). Genome-wide atlas of gene expression in the adult mouse brain. Nature 445: 168-176.

Lipina T, Labrie V, Weiner I, Roder J (2005). Modulators of the glycine site on NMDA receptors, D-serine and ALX 5407, display similar beneficial effects to clozapine in mouse models of schizophrenia. Psychopharmacology (Berl) 179: 54-67.

Lisman JE, Grace AA (2005). The hippocampal-VTA loop: controlling the entry of information into long-term memory. Neuron 46: 703.

Littlewood CL, Jones N, O’Neill MJ, Mitchell SN, Tricklebank M, Williams SC (2006). Mapping the central effects of ketamine in the rat using pharmacological MRI. Psychopharmacology (Berl) 186: $64-81$.

Lodge DJ, Grace AA (2007). Aberrant hippocampal activity underlies the dopamine dysregulation in an animal model of schizophrenia. J Neurosci 27: 11424-11430.

Maciejewski PK, Rothman DL (2008). Proposed cycles for functional glutamate trafficking in synaptic neurotransmission. Neurochem Int 52: 809-825.

Madl JE, Larson AA, Beitz AJ (1986). Monoclonal antibody specific for carbodiimide-fixed glutamate: immunocytochemical localization in the rat CNS. J Histochem Cytochem 34: 317-326.

Maeshima H, Ohnuma T, Sakai Y, Shibata N, Baba H, Ihara H et al (2007). Increased plasma glutamate by antipsychotic medication and its relationship to glutaminase 1 and 2 genotypes in schizophrenia - Juntendo University Schizophrenia Projects (JUSP). Prog Neuropsychopharmacol Biol Psychiatry 31: 1410-1418.

Malaspina D, Harkavy-Friedman J, Corcoran C, Mujica-Parodi L, Printz D, Gorman JM et al (2004). Resting neural activity distinguishes subgroups of schizophrenia patients. Biol Psychiatry 56: 931-937.

Martinez D, Slifstein M, Broft A, Mawlawi O, Hwang DR, Huang Y et al (2003). Imaging human mesolimbic dopamine transmission with positron emission tomography. Part II: amphetamineinduced dopamine release in the functional subdivisions of the striatum. J Cereb Blood Flow Metab 23: 285-300.

Masson J, Darmon M, Conjard A, Chuhma N, Ropert N, ThobyBrisson $\mathrm{M}$ et al (2006). Mice lacking brain/kidney phosphateactivated glutaminase (GLS1) have impaired glutamatergic synaptic transmission, altered breathing, disorganized goal-directed behavior and die shortly after birth. J Neurosci 26: $4660-4671$.

Matsuzaki S, Tohyama M (2007). Molecular mechanism of schizophrenia with reference to disrupted-in-schizophrenia 1 (DISC1). Neurochem Int 51: 165-172.

Medoff DR, Holcomb HH, Lahti AC, Tamminga CA (2001). Probing the human hippocampus using rCBF: contrasts in schizophrenia. Hippocampus 11: 543-550.

Miyamoto S, Leipzig JN, Lieberman JA, Duncan GE (2000). Effects of ketamine, MK-801, and amphetamine on regional brain 2deoxyglucose uptake in freely moving mice. Neuropsychopharmacology 22: 400-412.

Moghaddam B, Adams B, Verma A, Daly D (1997). Activation of glutamatergic neurotransmission by ketamine: a novel step in the pathway from NMDA receptor blockade to dopaminergic and cognitive disruptions associated with the prefrontal cortex. J Neurosci 17: 2921-2927.

Moghaddam B, Adams BW (1998). Reversal of phencyclidine effects by a group II metabotropic glutamate receptor agonist in rats. Science 281: 1349-1352.
Moghaddam B, Bolinao ML (1994). Glutamatergic antagonists attenuate ability of dopamine uptake blockers to increase extracellular levels of dopamine: implications for tonic influence of glutamate on dopamine release. Synapse 18: 337-342.

Moore H, Jentsch JD, Ghajarnia M, Geyer MA, Grace AA (2006). A neurobehavioral systems analysis of the effects of gestational exposure to methylazoxymethanol acetate (MAM) in the rat: implications for the neuropathology of schizophrenia. Biol Psychiatry 60: 253-264.

Moreno H, Wu WE, Lee T, Brickman A, Mayeux R, Brown TR et al (2007). Imaging the abeta-related neurotoxicity of Alzheimer disease. Arch Neurol 64: 1467-1477.

Morice R (1990). Cognitive inflexibility and pre-frontal dysfunction in schizophrenia and mania. Br J Psychiatry 157: 50-54.

Morris R (1984). Developments of a water-maze procedure for studying spatial learning in the rat. J Neurosci Methods 11: 47-60.

Moser PC, Hitchcock JM, Lister S, Moran PM (2000). The pharmacology of latent inhibition as an animal model of schizophrenia [In Process Citation]. Brain Res Rev 33: 275-307.

Najlerahim A, Harrison PJ, Barton AJ, Heffernan J, Pearson RC (1990). Distribution of messenger RNAs encoding the enzymes glutaminase, aspartate aminotransferase and glutamic acid decarboxylase in rat brain. Mol Brain Res 7: 317-333.

Nakazawa K, Quirk MC, Chitwood RA, Watanabe M, Yeckel MF, Sun LD et al (2002). Requirement for hippocampal CA3 NMDA receptors in associative memory recall. Science 297: 211-218.

Nilsson M, Waters S, Waters N, Carlsson A, Carlsson ML (2001). A behavioural pattern analysis of hypoglutamatergic mice-effects of four different antipsychotic agents. J Neural Transm 108: $1181-1196$.

O'Leary-Moore SK, Galloway MP, McMechan AP, Hannigan JH, Bowen SE (2007). Region-dependent alterations in glutamate and GABA measured by high-resolution magnetic resonance spectroscopy following acute binge inhalation of toluene in juvenile rats. Neurotoxicol Teratol 29: 466-475.

Olney JW, Newcomer JW, Farber NB (1999). NMDA receptor hypofunction model of schizophrenia. J Psychiatr Res 33: 523-533.

Paterlini M, Zakharenko SS, Lai WS, Qin J, Zhang H, Mukai J et al (2005). Transcriptional and behavioral interaction between 22q11.2 orthologs modulates schizophrenia-related phenotypes in mice. Nat Neurosci 8: 1586-1594.

Patil ST, Zhang L, Martenyi F, Lowe SL, Jackson KA, Andreev BV et al (2007). Activation of $m G l u 2 / 3$ receptors as a new approach to treat schizophrenia: a randomized phase 2 clinical trial. Nat Med 13: 1102-1107.

Paylor R, Crawley JN (1997). Inbred strain differences in prepulse inhibition of the mouse startle response. Psychopharmacology (Berl) 132: 169-180.

Pereira A, Huddleston D, Brickman A, Sosunov A, Hen R, McKhann $G$ et al (2007). An in vivo correlate of exerciseinduced neurogenesis in the adult dentate gyrus. Proc Natl Acad Sci USA 104: 5638-5643.

Razoux F, Garcia R, Lena I (2007). Ketamine, at a dose that disrupts motor behavior and latent inhibition, enhances prefrontal cortex synaptic efficacy and glutamate release in the nucleus accumbens. Neuropsychopharmacology 32: 719-727.

Remondes M, Schuman EM (2004). Role for a cortical input to hippocampal area CA1 in the consolidation of a long-term memory. Nature 431: 699-703.

Roiser JP, Stephan KE, Ouden HE, Barnes TR, Friston KJ, Joyce EM (2009). Do patients with schizophrenia exhibit aberrant salience? Psychol Med 39: 199-209 Epub 2008 Jun 30.

Rorick-Kehn LM, Johnson BG, Knitowski KM, Salhoff CR, Witkin $\mathrm{JM}$, Perry KW et al (2007). In vivo pharmacological characterization of the structurally novel, potent, selective mGlu2/3 
receptor agonist LY404039 in animal models of psychiatric disorders. Psychopharmacology (Berl) 193: 121-136.

Saxe MD, Malleret G, Vronskaya S, Mendez I, Garcia AD, Sofroniew MV et al (2007). Paradoxical influence of hippocampal neurogenesis on working memory. Proc Natl Acad Sci USA 104: 4642-4646.

Schobel SA, Lewandowski NM, Corcoran C, Moore H, Brown T, Malaspina D et al (2009). The CA1 subfield of the hippocampal formation is differentially targeted by schizophrenia and related psychotic disorders. Arch Gen Psychiatry In press.

Seiferth NY, Pauly K, Habel U, Kellermann T, Shah NJ, R uhrmann $S$ et al (2008). Increased neural response related to neutral faces in individuals at risk for psychosis. Neuroimage 40: 289-297.

Sharma N, Baxter MG, Petravicz J, Bragg DC, Schienda A, Standaert DG et al (2005). Impaired motor learning in mice expressing torsin A with the DYT1 dystonia mutation. J Neurosci 25: 5351-5355.

Sherman AD, Hamrah M, Mott J (1988). Effects of neuroleptics on glutaminase from rat synaptosomes. Neurochem Res 13: 535-538.

Soyka M, Koch W, Moller HJ, Ruther T, Tatsch K (2005). Hypermetabolic pattern in frontal cortex and other brain regions in unmedicated schizophrenia patients. Results from a FDG-PET study. Eur Arch Psychiatry Clin Neurosci 255: 308-312.

Steffek AE, McCullumsmith RE, Haroutunian V, Meador-Woodruff JH (2008). Cortical expression of glial fibrillary acidic protein and glutamine synthetase is decreased in schizophrenia. Schizophr Res 103: 71-82.

Takahata R, Moghaddam B (2003). Activation of glutamate neurotransmission in the prefrontal cortex sustains the motoric and dopaminergic effects of phencyclidine. Neuropsychopharmacology 28: 1117-1124.
Tamminga CA, Lahti AC, Medoff DR, Gao XM, Holcomb HH (2003). Evaluating glutamatergic transmission in schizophrenia. Ann N Y Acad Sci 1003: 113-118.

Tiihonen J, Hallikainen T, Ryyna?nen OP, Repo-Tiihonen E, Kotilainen I, Eronen M et al (2003). Lamotrigine in treatmentresistant schizophrenia: a randomized placebo-controlled crossover trial. Biol Psychiatry 54: 1241-1248.

Titone D, Levy DL, Holzman PS (2000). Contextual insensitivity in schizophrenic language processing: evidence from lexical ambiguity. J Abnorm Psychol 109: 761-767.

Tordera RM, Totterdell S, Wojcik SM, Brose N, Elizalde N, Lasheras B et al (2007). Enhanced anxiety, depressive-like behaviour and impaired recognition memory in mice with reduced expression of the vesicular glutamate transporter 1 (VGLUT1). Eur J Neurosci 25: 281-290.

Weiner I (2003). The 'two-headed' latent inhibition model of schizophrenia: modeling positive and negative symptoms and their treatment. Psychopharmacology (Berl) 169: 257-297.

Weiner I, Shadach E, Barkai R, Feldon J (1997). Haloperidol- and clozapine-induced enhancement of latent inhibition with extended conditioning: implications for the mechanism of action of neuroleptic drugs. Neuropsychopharmacology 16: 42-50.

Yano H, Ninan I, Zhang H, Milner TA, Arancio O, Chao MV (2006). BDNF-mediated neurotransmission relies upon a myosin VI motor complex. Nat Neurosci 9: 1009-1018.

Yee BK, Balic E, Singer P, Schwerdel C, Grampp T, Gabernet L et al (2006). Disruption of glycine transporter 1 restricted to forebrain neurons is associated with a procognitive and antipsychotic phenotypic profile. J Neurosci 26: 3169-3181.

Zhang B, Yuan Y, Jia Y, Yu X, Xu Q, Shen Y et al (2005). An association study between polymorphisms in five genes in glutamate and GABA pathway and paranoid schizophrenia. Eur Psychiatry 20: 45-49.

Supplementary information accompanies the paper on the Neuropsychopharmacology website (http://www.nature.com/npp) 